\title{
REVIEW
}

\section{Small airways diseases, excluding asthma and COPD: an overview}

\author{
Pierre-Régis Burgel, Anne Bergeron, Jacques de Blic, Philippe Bonniaud, \\ Arnaud Bourdin, Pascal Chanez, Thierry Chinet, Jean-Charles Dalphin, \\ Philippe Devillier, Antoine Deschildre, Alain Didier, Marianne Kambouchner, \\ Christiane Knoop, François Laurent, Hilario Nunes, Thierry Perez, Nicolas Roche, \\ Isabelle Tillie-Leblond ${ }^{\dagger}$ and Daniel Dusser
}

ABSTRACT: This review is the summary of a workshop on small airways disease, which took place in Porquerolles, France in November 2011. The purpose of this workshop was to review the evidence on small airways (bronchiolar) involvement under various pathophysiological circumstances, excluding asthma and chronic obstructive pulmonary disease. Histopathological patterns associated with small airways disease were reviewed, including cellular and obliterative bronchiolitis. Many pathophysiological conditions have been associated with small airways disease including airway infections, connective tissue diseases and inflammatory bowel diseases, bone marrow and lung transplantation, common variable immunodeficiency disorders, diffuse panbronchiolitis, and diseases related to environmental exposures to pollutants, allergens and drugs. Pathogenesis, clinical presentation, a computed tomography scan and pulmonary function test findings are reviewed, and therapeutic options are described with the objective of providing an integrative approach to these disorders.

KEYWORDS: Airway pathology, connective tissue disease, constrictive bronchiolitis, druginduced lung disease, follicular bronchiolitis, immune deficiency

$\mathbf{T}$ he present article is a summary of a workshop on small airways disease, which took place in Porquerolles, France, in November 2011. Data reviewed during the workshop were updated with articles published in 2012. The purpose of this workshop was to review the evidence on small airways (bronchiolar) involvement under various pathophysiological circumstances, excluding asthma and chronic obstructive pulmonary disease, which have been the subject of previous publications [1-3]. Cystic fibrosis (which is also characterised by both small and large airways involvement [4, 5]) is not discussed in the present article. Histopathological patterns associated with small airways disease were reviewed, including cellular and obliterative bronchiolitis. Many pathophysiological conditions have been associated with small airways disease and not all conditions can be discussed in a single review article. We chose to focus on the major causes of small airways disease including airway infections, connective tissue diseases and inflammatory bowel diseases, bone marrow and lung transplantation, immune deficiencies, diffuse panbronchiolitis, and diseases related to environmental exposures to pollutants, allergens and drugs. Our objective was to provide an integrative approach to these disorders by describing clinical presentation, computed tomography (CT) scan and pulmonary function test findings, and therapeutic options.

\section{OVERVIEW OF SMALL AIRWAYS DISEASE}

Small airways are usually defined as noncartilaginous airways with an internal diameter $<2 \mathrm{~mm}$ [3]. These airways are located from approximately the eighth generation of airways down to the terminal bronchioles (the smallest airways without alveoli) and respiratory bronchioles, which open into the gas-exchange apparatus (the alveoli). In normal lungs, small airways contribute only a little to total airway resistance [6], and it has been estimated that obstruction of $75 \%$ of all small airways is required before changes can be detected by routine pulmonary function tests (e.g. forced expiratory volume in
AFFILIATIONS

For a full list of affiliations see the Acknowledgements section.

CORRESPONDENCE

D. Dusser

Service de Pneumologie

Hôpital Cochin

27 rue du Faubourg St Jacques

75679 Paris Cedex 14

France

E-mail: daniel.dusser@cch.aphp.fr

Received:

March 122013

Accepted:

March 292013

PROVENANCE

Publication of this peer-reviewed article was supported by Chiesi SA, France (article sponsor, European Respiratory Review issue 128). 
$1 \mathrm{~s}$ (FEV1)) [7]. Small airways are not easily visualised by imaging techniques and their histopathological analysis is best analysed in surgical lung biopsies because bronchoscopic transbronchial biopsies usually contain only a few small airways. The difficulties of sampling these airways in human subjects are responsible for the limited recognition of the important pathophysiological roles of small airways, which have been called the "silent zone". Small airways appear particularly vulnerable because many particles and infectious agents may be deposited there and because their narrow lumen makes them more susceptible to complete obstruction than larger airways. These considerations explain why: 1) small airways involvement occurs in many diseases either isolated or in association with abnormalities in large airways and alveoli; and 2) small airways represent the major site of airflow limitation in most airways diseases [6].

Small airways disease (bronchiolitis) corresponds to a relatively limited number of elementary lesions. A classification of bronchiolitis has been proposed based on aetiology and histopathological appearance (table 1) [8]. However, this classification was largely based on the results of histopathological examination, which requires bronchoscopic or surgical biopsy that cannot be performed in all patients. Improvement in CT imaging has led to the proposal of a noninvasive diagnostic algorithm that may obviate the requirement for biopsy in some patients [9]. Although these classifications or algorithm are helpful to physicians, no single classification can fully cover the spectrum of possible causes associated with small airways disease. The diagnosis of small airways disease has to rely on integration of multiple data including clinical context and medical history, CT scan pattern and pulmonary function tests. In selected cases, histological findings will improve diagnostic accuracy, but bronchoscopic or surgical lung biopsy is not always possible or necessary. Finally, response to therapy may provide additional information, e.g.

\section{TABLE 1 Histological classification of bronchiolar disorders}

Primary bronchiolar disorders

Constrictive bronchiolitis (obliterative bronchiolitis and bronchiolitis obliterans)

Acute bronchiolitis

Diffuse panbronchiolitis

Respiratory bronchiolitis (smoker's bronchiolitis)

Mineral dust airway disease

Follicular bronchiolitis

Other primary bronchiolar disorders, e.g. diffuse aspiration bronchiolitis and lymphocytic bronchiolitis

Interstitial lung disease with a prominent bronchiolar involvement

Hypersensitivity pneumonitis

Respiratory bronchiolitis-associated interstitial lung disease

Cryptogenic organising pneumonia

Other interstitial lung disease (pulmonary Langherans' cell

hystiocytosis, sarcoidosis and bronchiolocentric interstitial pneumonia)

Bronchiolar involvement in diseases also involving large airways

Chronic obstructive pulmonary disease

Bronchiectasis, including cystic fibrosis

Asthma

Adapted from [8] with permission from the publisher. prolonged macrolide therapy may induce dramatic improvement in subjects with diffuse panbronchiolitis.

\section{Pathology of small airways disease}

The pathology of small airways disease has been reviewed previously [8, 10-12] and, therefore, will not be extensively discussed here. Histopathological analysis of small airways disease usually requires surgical lung biopsy that allows examination of multiple small airways, whereas transbronchial biopsy only samples small numbers of airways. A limited number of elementary lesions are described in diseases associated with small airways involvement (fig. 1).

Cellular bronchiolitis is characterised by the recruitment of inflammatory cells in the small airways wall. In some cases, cellular infiltrate may show a specific organisation (e.g. granulomas or lymphoid follicles), leading to specific denominations (e.g. granulomatous bronchiolitis and follicular bronchiolitis). Granulomatous bronchiolitis is most frequently associated with tuberculosis or infection with nontuberculous mycobacteria, but can also be observed in sarcoidosis or hypersensitivity pneumonitis. Follicular bronchiolitis is characterised by the presence of lymphoid follicles (i.e. tertiary lymphoid structures containing B- and T-lymphocytes and dendritic cells with a specific organisation). Although follicular bronchiolitis has been particularly associated with Sjögren's disease (see later section) [13], it may be observed in other diseases, including common variable immunodeficiency disorder (CVID) [14] and hypersensitivity pneumonitis, and has sometimes been described in the context of bacterial infection (e.g. Legionella pneumophila) [15]. Hypertrophic or confluent lymphoid follicles may result in compression of the small airways, leading to a reduction in their cross-sectional area.

The term "bronchiolitis obliterans" has been previously used for describing a wide range of histopathological lesions resulting in small airways lumen narrowing, and is still used for describing the clinical syndrome characterised by progressive and poorly reversible airflow limitation under some circumstances (e.g. lung transplantation). Histopathological use of the term bronchiolitis obliterans appears limited to a form of proliferative bronchiolitis, characterised by the presence of fibro-inflammatory polyps obstructing the small airways lumen. These lesions are often associated with endoalveolar fibro-inflammatory polyps, which are characteristic of organising pneumonia [8]. By contrast, obliterative (also called constrictive) bronchiolitis is characterised by narrowing of small airways related to patchy peribronchiolar fibrosis, which surrounds rather than fills the lumen [8].

Other lesions may be associated with small airways disease, but have been suggested to be consequences rather than causes of the disease. Mucoid impaction results from mucous plugging in small airways related to goblet cell hyperplasia [16]. Peribronchiolar metaplasia is a common histological finding in various interstitial disorders and sometimes occurs as an isolated finding [17]. Formation of cysts (thin-walled cystic airspace) has been described in various diseases (e.g. Sjögren's syndrome and hypersensitivity pneumonitis) and was suggested to be a consequence of small airways obstruction [18].

Importantly, various elementary lesions may coexist in a single patient but the pathological classification does not always 

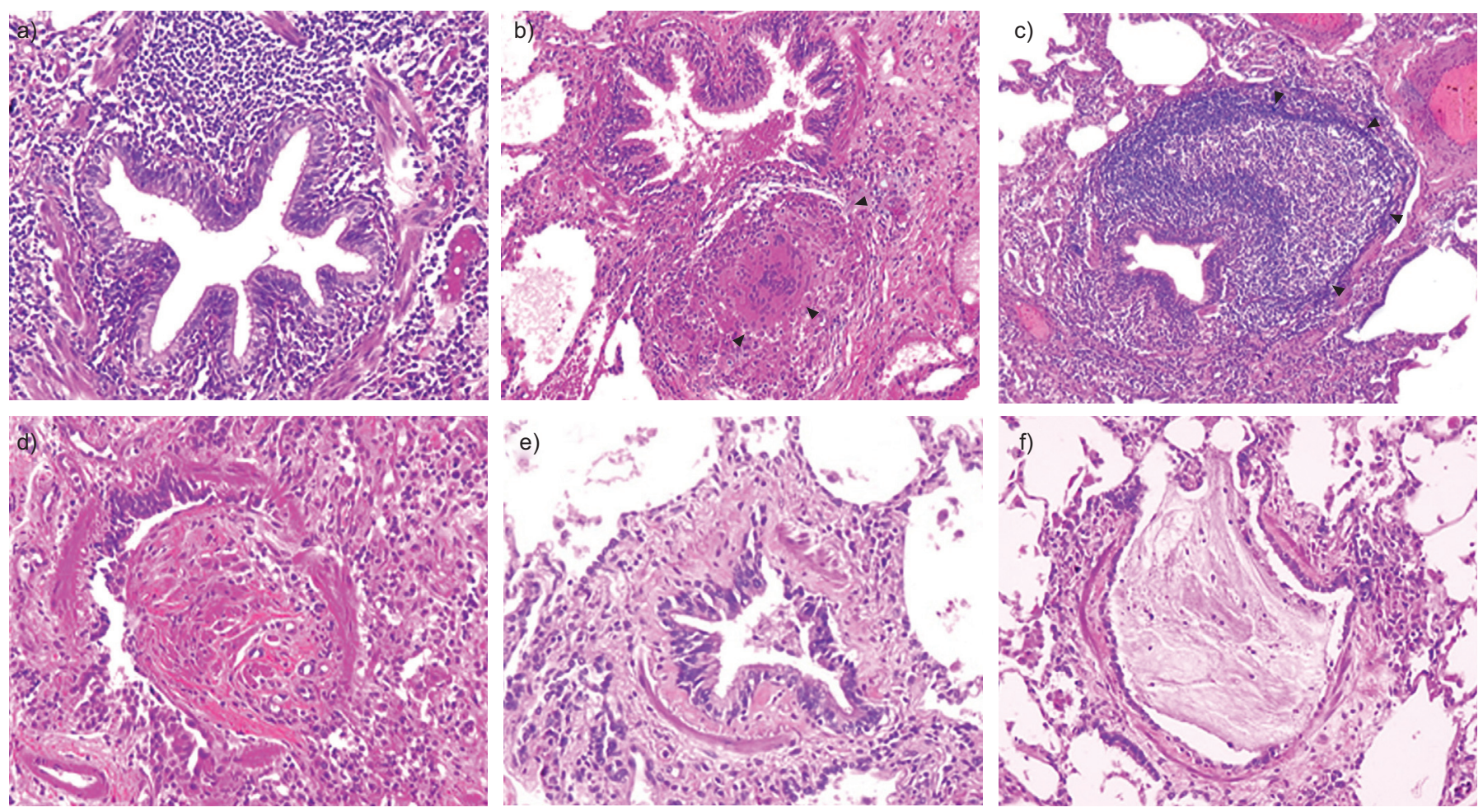

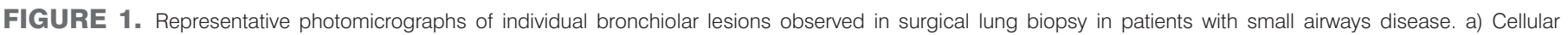

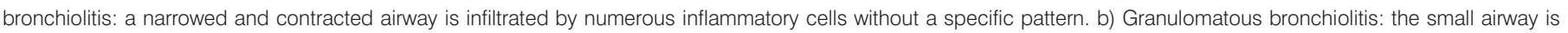

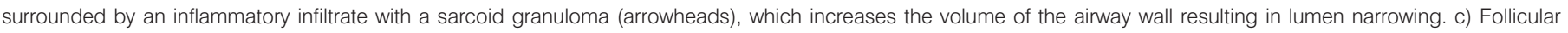

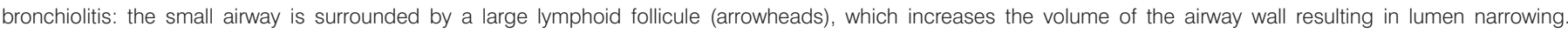

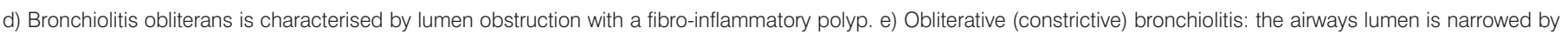

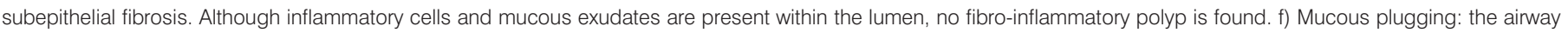
lumen is obstructed by mucus exudates.

reflect clinical diagnosis. Nevertheless, histological description can be rather specific of some aetiology. Respiratory bronchiolitis, which occurs in current smokers, may be isolated or associated with interstitial lung disease (ILD). It is characterised by patchy inflammatory bronchiolitis containing pigmented macrophages with a predominant upper lobe distribution, and is eventually associated with interstitial inflammatory changes [8]. Diffuse panbronchiolitis also has characteristic features.

\section{Imaging of small airways disease}

Potential interest and limitations of the various imaging techniques that can be used for the diagnosis of small airways disease have been described previously [1-3]. Volumetric CT scans with thin sections $(0.75-1.25 \mathrm{~mm})$ allow multiplanar coronal or sagittal reconstructions with maximum intensity projection (MIP) and minimum intensity projection (minIP) images, and is the preferred imaging technique in subjects suspected of small airways disease [9]. Inspiratory and expiratory acquisitions are routinely obtained for assessing small airways using qualitative analysis. To date, quantitative analysis based on measurements of voxel attenuation values has only been used for research purposes. Novel voxel-wise image analysis techniques (e.g. parametric response map) are currently being developed and may provide improved assessment of small airways disease in the near future [19].
The spatial resolution on a CT scan is $\sim 0.6-1 \mathrm{~mm}$, which allows direct assessment of medium-sized airways (diameter 2-2.5 mm), but not of smaller airways. Thus, normal bronchioles are not visible on CT scans. Small airways disease may show direct or indirect signs on a CT scan [20]. Direct signs of small airways disease include ill-defined centrilobular nodules and well-defined centrilobular branching nodules, also called tree-in-bud opacities, which may be best seen using MIP. Indirect signs of small airways disease include a mosaic pattern of attenuation (on inspiratory CT scan) and air trapping (on expiratory CT scan and best seen using minIP). Representative CT scan images are presented in figure 2. Because centrilobular nodules and tree-in-bud opacities have been mostly associated with cellular bronchiolitis, whereas mosaic pattern of attenuation and trapping have been mostly associated with obliterative (constrictive) bronchiolitis, DEVAKONDA et al. [9] have recently proposed a diagnostic algorithm based on clinical context and CT findings. The authors proposed that tree-in-bud opacities suggest infectious aetiology, whereas ill-defined centrilobular nodules suggest respiratory bronchiolitis when localised in upper lobes in smokers and hypersensitivity pneumonitis when more diffuse [9]. The authors further proposed that mosaic pattern of attenuation and air trapping are suggesting of constrictive/ obliterative bronchiolitis [9]. This proposal may be useful considering that most patients with suspected small airways 

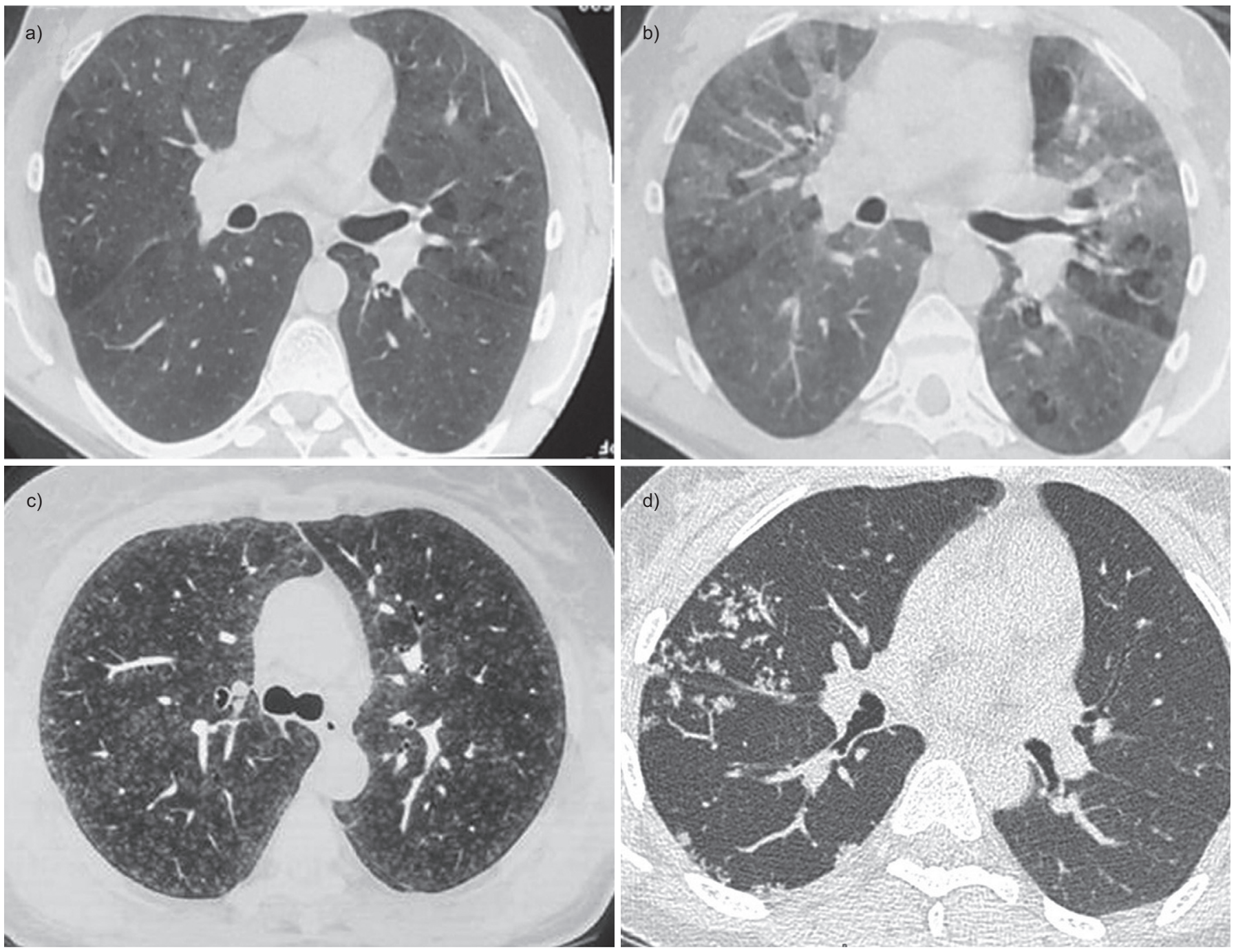

FIGURE 2. Representative images of computed tomography (CT) scans in patients with small airways disease. a) An inspiratory CT scan in a patient with hypersensitivity pneumonitis showing mosaic pattern of attenuation. b) Expiratory CT scan in the same patient showing air trapping that is characteristic of small airways disease. c) III-defined centrilobular nodules in a patient with farmer's lung (personal communication; J.C. Dalphin). d) Localised micronodules branching with bronchovascular structures (tree-inbud pattern) related to tuberculosis in a patient with rheumatoid arthritis receiving treatment with anti-tumour necrosis factor- $\alpha$. Reproduced from [21] with permission from the publisher.

disease will not have surgical lung biopsy, but this algorithm has not yet been prospectively validated.

\section{SPECIFIC CAUSES OF SMALL AIRWAYS DISEASES Infection}

Post-infectious bronchiolitis is characterised by persistent inflammatory infiltrate and fibrotic lesions of small airways following a pulmonary infection and leads to airflow obstruction. It represents a rare cause of chronic airflow limitation. Because obstruction in a large number of small airways may occur before airflow limitation can be detected using conventional pulmonary function tests [22], post-infectious bronchiolitis is probably underestimated when damage to small airways affects localised areas of the lungs. Clinical features differ between children and adults. Adenovirus (especially serotypes 3, 7 and 21, which are more virulent $[23,24]$ ) is an infectious agent frequently involved in children $[25,26]$. Other infectious agents responsible for post-infectious bronchiolitis in children include viruses (e.g. measles and influenza) and intracellular bacteria (e.g. Mycoplasma pneumoniae) [27-29]. The prospective study by COLOM et al. [30] indicates that adenovirus infection is by far the most important risk factor for postinfectious bronchiolitis, especially in cases of severe acute disease requiring mechanical ventilation.

Diagnosis of post-infectious bronchiolitis in children is based on medical history, CT scans and pulmonary function tests. Clinical manifestations are nonspecific and include cough, sputum production, dyspnoea and wheezing. These manifestations typically occur a few weeks after an episode of lower airways viral infection. A CT scan may show mosaic attenuation, air trapping, bronchial thickening, bronchiectasis, atelectasis and/or mucoid impaction [31]. Swyer-James MacLeod's syndrome corresponds to unilateral small hyperlucent lung, caused by asymmetric obliterative bronchiolitis with air trapping and diminished arterial flow. Pulmonary function 
tests usually show airflow limitation and hyperinflation, which are poorly reversible with bronchodilators [32, 33].

The treatment of post-infectious bronchiolitis in children is mostly symptomatic; systemic steroids do not appear efficacious after the initial stage of acute infection, when bronchiolitis is usually diagnosed. Most severe cases may result in chronic respiratory insufficiency that sometimes requires lung transplantation [27].

In adults, the frequency of small airways disease in the context of lung infection is unclear, but appears less frequent than in children. Most reports describe post-infectious bronchiolitis obliterans with organising pneumonia (BOOP), which usually recovers spontaneously or with oral steroids [34]. Nevertheless, constrictive (obliterative) bronchiolitis is also described after viral (e.g. respiratory syncytial virus) [35] or bacterial (Legionella, M. pneumoniae) infection [36, 37], and is suggested to not respond as well as BOOP to systemic steroids [38]. Localised small airways disease, usually characterised by tree-in-bud opacities on CT scans, is also described in the context of tuberculosis or infection with nontuberculous mycobacteria [9].

\section{Connective tissue diseases}

Bronchiolar complications of connective tissue diseases are less well recognised than other pulmonary complications (e.g. ILD and pleural disease) of these disorders [39]. Sjögren's syndrome [40] and rheumatoid arthritis [41] are the two most frequent connective tissue diseases, in which bronchial and bronchiolar complications are found. Small airways disease may also occur in chronic inflammatory bowel diseases [42], as well as in other connective tissue diseases (e.g. scleroderma and systemic lupus), vasculitis or sarcoidosis [43]. Because the incidence of small airways disease is by far less frequent in these latter diseases, they will not be discussed in the present article.

Bronchiolitis in connective tissue diseases belongs to bronchiolitis of unknown origin in a well-defined context. However, it should be emphasised that the diagnosis of Sjögren's syndrome or rheumatoid arthritis may not be previously established in a patient with chronic cough or bronchial hyperresponsiveness, and that these diagnoses should be considered in patients with unexplained cough. Both follicular bronchiolitis and constrictive bronchiolitis may be encountered in subjects with connective tissue diseases and may even coexist in the same patient $[41,44]$. CT scan findings in Sjögren's syndrome and in rheumatoid arthritis have been the subject of many studies [44-54], and are characterised by usual signs of small airways abnormalities, including mosaic attenuation on inspiratory $\mathrm{CT}$, air trapping on expiratory $\mathrm{CT}$, ground-glass opacities, and centrilobular nodules eventually with tree-in-bud pattern (especially in cellular bronchiolitis) or distension (especially in constrictive bronchiolitis). CT scans may have better sensitivity than pulmonary function tests in rheumatoid arthritis [52]. Signs of infiltrative lung disease or large bronchi involvement may be associated with signs of small airways disease [55]. Pulmonary function tests usually show poorly reversible airflow limitation that may be preceded by distal airflow limitation, as suggested by reduced forced expiratory flow at $25-75 \%$ of forced vital capacity (FVC) (FEF25-75\%) or at 50\% of FVC (FEF50\%) [52].

\section{Sjögren's syndrome}

Sjögren's syndrome is characterised by abnormal function and/or destruction of exocrine glands related to infiltration by T-lymphocytes. Although salivary and lacrimal glands are most frequently involved, respiratory manifestations are frequent, varying from $9 \%$ to $75 \%$ of patients, due to the inclusion of different types of patients and the use of different methods to assess respiratory disease. Most studies and case reports have focused on infiltrative pneumonia, but small airways involvement actually seems more frequent. PAPIRIS et al. [56] studied airway inflammation in 13 nonsmoking patients with Sjögren's syndrome using bronchial and transbronchial biopsies. 10 patients had infiltration of bronchi and bronchiole submucosa by lymphocytes, which were CD4+Tlymphocytes in six patients [56]. Another study described neutrophils and mast cells in the bronchi of patients with primary Sjögren's syndrome [57]. Finally, a Japanese study found no difference in cells infiltrating small airways between primary and secondary Sjögren's syndromes [58].

Small airways disease in Sjögren's disease may be isolated or associated with nonspecific interstitial pneumonia (NSIP) or lymphoid interstitial pneumonia (LIP). Iто et al. [51] studied radiological and pathological findings in 33 subjects with pulmonary manifestations of primary Sjögren's syndrome. In four out of 33 cases small airways involvement was predominant, and in an additional four out of 33 cases it was associated with other abnormalities. The authors concluded that $25 \%$ of patients with primary Sjögren's syndrome had small airways abnormalities [51]. The most prevalent pathological pattern in the small airways of patients with Sjögren's syndrome is follicular bronchiolitis, in which peribronchiolar lymphoid follicles may obstruct bronchiolar lumens. Sjögren's syndrome and rheumatoid arthritis are the systemic diseases that are most closely associated with follicular bronchiolitis [59]. Other pathological patterns found in Sjögren's disease include lymphocytic (cellular) bronchiolitis (in which lymphocytes infiltrate the small airways wall without forming lymphoid follicles [60]); obliterative bronchiolitis is rarely found in primary Sjögren's syndrome, but may be observed in patients with secondary Sjögren's syndrome-associated with rheumatoid arthritis [58].

Chronic cough is present in $\sim 50 \%$ of patients with primary Sjögren's syndrome [61] and may be related to bronchitis and bronchiolitis, but also to bronchial hyperresponsiveness that occurred in $42-60 \%$ of patients in several studies [62-64]. Mechanisms underlying bronchial hyperresponsiveness in patients with primary Sjögren's syndrome probably differ from those in asthmatic patients [65], but remain unknown. Chronic sputum production and recurring sinusitis are associated with severe chronic bronchiolitis in primary Sjögren's syndrome [66].

CT scans in Sjögren's syndrome often shows abnormalities in large airways (airway wall thickening and bronchiectasis) together with indirect signs of abnormalities in small airways (centrilobular nodules and expiratory air trapping) [48, 53, 58, 67-70].

Therapeutic options and prognosis factors in Sjögren's syndrome-associated small airways disease are not well defined. Although systemic steroids have been proposed by 
some authors, it does not appear efficacious in most cases [51]. Low-dose macrolides have been proposed in subjects with bronchiolitis related to rheumatoid arthritis [41] and may be proposed in Sjögren's syndrome [65]. Inhaled steroids and long-acting bronchodilators could be proposed in patients with bronchial hyperresponsiveness, although one study suggested that this approach is not very effective in Sjögren's syndrome [71]. Treatment with rituximab could represent a therapeutic option in subjects with aggressive, severe disease [72].

\section{Rheumatoid arthritis}

Large and small airways involvement is a classic feature in subjects with rheumatoid arthritis. The only identified risk factors for airways involvement in rheumatoid arthritis are mutations in the cystic fibrosis transmembrane conductance regulator (CFTR) gene [73, 74]. Although the pathophysiological link between airways involvement in rheumatoid arthritis and CFTR mutations is unclear, heterozygous mutations in the CFTR gene have been associated with CFTR dysfunction and airways disease [75]. Surprisingly, some studies have found associations of small airways disease in rheumatoid arthritis with the absence of significant smoking history [45, 50, 52], a finding that may be related to bias in retrospective studies.

Rheumatoid arthritis is considered the most frequent connective tissue disease associated with small airways disease. However, diagnostic criteria varied among studies and the choice of criteria has a major effect on epidemiological description. GEDDES et al. [76] reported that 32\% of patients with rheumatoid arthritis had airflow limitation. TANAKA et al. [44] found that $17 \%$ of patients had CT scan features suggestive of bronchiolitis. In other studies, the prevalence of small airways abnormalities ranged from 8-65\% [41, 45, 52, 77, 78]. PEREz et al. [52] suggested that CT scans have increased sensitivity for the detection of air trapping compared with pulmonary function tests, whereas MorI et al. [79] showed that $30 \%$ of patients with normal findings on CT scans have a significant reduction in FEF25-75\%. Respiratory symptoms appeared more prevalent in subjects with small airways abnormalities [52]. It is possible that drugs, historically used for rheumatoid arthritis ( $D$-penicillamine, tiopronin or chrysotherapy), promoted the development of bronchiolitis in some patients (see later section) [80,81].

Few studies have evaluated histopathological findings in subjects with rheumatoid arthritis-associated bronchiolitis. HAYAKAWA et al. [41] reported 15 cases, including seven cases of constrictive bronchiolitis and eight of follicular bronchiolitis. In a French collaborative study, DevouAssoux et al. [55] studied 25 patients with rheumatoid arthritis and severe airflow limitation: 18 patients had FEV1/FVC $<50 \%$; two patients had residual volume (RV)/total lung capacity $>140 \%$; and five patients had both criteria. Among nine patients with lung biopsy, histopathological patterns were constrictive bronchiolitis in six patients, follicular bronchiolitis in one patient and an association of both patterns in two patients [55]. There is no evidence that follicular bronchiolitis may precede constrictive bronchiolitis; furthermore, it is likely that constrictive bronchiolitis was more prevalent in this series because lung biopsies were mostly proposed to patients with more severe disease.
Finally, cases of diffuse panbronchiolitis have been described in Japanese patients with rheumatoid arthritis [82].

In the study by DevouAssoux et al. [55], bronchiolitis occurred 1-35 years after the diagnosis of rheumatoid arthritis in 22 out of 25 patients and was diagnosed essentially in females $(n=18)$. Clinical manifestations of severe bronchiolitis in patients with rheumatoid arthritis included dyspnoea in all patients, chronic cough (64\%) and chronic sputum production (44\%) [55]. A CT scan revealed bronchial wall thickening $(96 \%)$, mosaic pattern $(42 \%)$, ground-glass opacities (44\%) and centrilobular emphysema $(56 \%$, which was mostly found in patients with constrictive bronchiolitis) [55]. During follow-up (48 \pm 49 months), symptoms increased in $52 \%$ of patients, with respiratory infections in $60 \%$, pneumothorax in $12 \%$ and acute respiratory failure in $48 \%$. Chronic respiratory failure (as defined by the need of long-term oxygen therapy) occurred in $40 \%$ of patients, including four patients who died of respiratory failure [55]. In another series that evaluated 144 patients with rheumatoid arthritis and respiratory manifestations, 5-year survival rates were $36 \%$ in 57 patients with usual interstitial pneumonia, $87 \%$ in 31 patients with bronchiectasis, $94 \%$ in 16 patients with NSIP and $89 \%$ in 11 patients with bronchiolitis [83]. It is concluded that bronchiolitis is associated with poor prognosis essentially in patients with severe airflow limitation and marked hyperinflation, and that these features mostly occurred in patients with obliterative (rather than follicular) bronchiolitis.

At present, there is no validated treatment regimen in patients with severe small airways disease associated with rheumatoid arthritis. A trial of systemic steroids may be discussed, but obliterative bronchiolitis usually does not improve with steroids or other immunosuppressive drugs. Case reports suggest that etanercept [84] or low-dose macrolides [41] may show some benefit. In most severe cases, lung transplantation may be proposed [55].

\section{Inflammatory bowel diseases}

Because the lung and the gastrointestinal tract both originate from the foregut, it is not surprising that inflammatory bowel diseases (e.g. Crohn's disease and ulcerative colitis) could be associated with pulmonary manifestations. Although abnormalities in large airways (e.g. bronchiectasis) are prevalent in these diseases, bronchiolitis has also been described [85, 86]. When present, respiratory manifestations usually occur in patients already diagnosed with inflammatory bowel disease, sometimes after colectomy [87]. Pulmonary function tests are often abnormal in patients with inflammatory bowel disease, but symptoms are less prevalent and the disease is often asymptomatic [88]. In Crohn's disease, granulomatous bronchiolitis may occur and is usually associated with ILD, although a single case of isolated granulomatous bronchiolitis has been reported [42]. Severe obliterative bronchiolitis is a rare complication of ulcerative colitis [89].

\section{Transplantation}

Bronchiolitis obliterans is the most common disease affecting small airways after lung transplantation. It also occurs in patients with allogeneic (but not autogenic) haematopoietic stem cell transplantation (HSCT). Clinical manifestations of bronchiolitis obliterans after transplantation include progressive dyspnoea, eventually associated with chronic cough and 
sputum production, and progressive airflow limitation that may result in respiratory failure. Bronchiolitis obliterans after lung transplantation and after allogeneic HSCT are different diseases, but share some features (table 2). Confirmation of the diagnosis of bronchiolitis obliterans requires histopathological examination. Bronchiolitis obliterans after lung transplantation is characterised by intraluminal polyps comprised of fibromyxoid granulation tissue and plaques of dense submucosal eosinophilic scar [90]. However, histopathological confirmation of bronchiolitis obliterans may be difficult to obtain because open-lung biopsy is seldom performed and transbronchial biopsy has poor sensibility for the diagnosis of bronchiolitis obliterans due to the small size of samples and the focal nature of this disease. The International Society for Heart and Lung Transplantation (ISHLT) has proposed the term bronchiolitis obliterans syndrome (BOS) for patients with clinical manifestations compatible with bronchiolitis obliterans but without histopathological confirmation [90]. By analogy, BOS is often used after allogeneic stem cell transplantation.

\section{Bronchiolitis obliterans after lung transplantation}

Bronchiolitis obliterans is the main complication after lung transplantation and is the first cause of death after the first year of transplantation [91]. The ISHLT Registry shows that at 1, 3, 5 and 10 years from transplantation, $90 \%, 70 \%, 50 \%$ and $30 \%$ of patients, respectively, have no clinical manifestations of bronchiolitis obliterans [91]. Median survival appears longer in patients with slow and delayed onset of airflow limitation after lung transplantation [92].

Two phenotypes of patients with bronchiolitis obliterans after lung transplantation have been identified, although intermediate phenotypes may exist. The first phenotype comprises patients with dyspnoea, chronic cough and purulent sputum production. Lung auscultation often reveals crackles and CT scans show air trapping on expiration, mucoid impaction and bronchiectasis. In these patients, airway neutrophilia is often prominent and azithromycin may have a beneficial effect on lung function. The second phenotype comprises patients with isolated dyspnoea, normal auscultation and isolated air trapping on expiratory CT scans. These patients have no significant airway neutrophilia and do not respond favourably to azithromycin [93].

Incidence of BOS is not associated with the clinical characteristics of the donor and the receiver, the type of lung transplant (single versus double lung transplantation) or the underlying pulmonary disease leading to transplantation [94]. Acute rejection (including low-grade vascular rejection [95-97]) appears to be the main factor associated with BOS [98]. However, acute rejection is not always associated with BOS and some patients with BOS had no previous acute rejection. Development of class I or class II donor-specific anti-human leukocyte antigen (HLA) antibodies is also associated with an increased risk of BOS [99]. Cytomegalovirus (CMV) pneumonia and CMV mismatch between CMV-positive donor and CMV-negative receivers have been associated with BOS in some [100], but not all, studies [101]. Community-acquired respiratory virus infections have also been associated with BOS [102], although a recent meta-analysis did not confirm this association [103], probably due to the heterogeneity of published studies. Gastro-oesophageal reflux disease (GORD) is a risk factor for BOS and retrospective studies suggest that surgical fundoplication in the first 3 months after transplantation prevents BOS [104], and that fundoplication may improve lung function in patients with established BOS [105]. A recent prospective study has shown that fundoplication results in improved lung function at 1 year posttransplantation, as compared with medical therapy in patients with clinically significant GORD [106].

\section{Risk factors \\ Immunology \\ Cytomegalovirus infection \\ Community-acquired viral infections \\ GORD}

Prevalence

Clinical presentation

Heterogeneous

Pathology

Treatment

Immunosuppression

Azithromycin

Surgical treatment of GORD

Lung (re)tranplantation

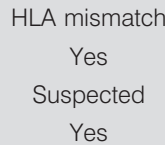

$9 \%$ at 1 year

$38 \%$ at 5 years

$58 \%$ at 10 years

Yes, two phenotypes

Heterogeneous

Optimisation

No increase

In subjects with alveolar neutrophilia

Yes

In selected patients
GVH disease

Not established

Suspected

Not established

$5.5 \% ; 14 \%$ in patients with GVH disease

Yes

Heterogeneous

Optimisation

No increase

Not established

Not established

In selected patients

GORD: gastro-oesophageal reflux disease; HLA: human leukocyte antigen; GVH: graft-versus-host. 
Pathogenesis of bronchiolitis obliterans after lung transplantation remains incompletely understood. Classically, bronchiolitis obliterans has been considered as the expression of chronic lung rejection. This concept has evolved since non-immunological risk factors (see above) have been identified. It seems possible that bronchiolitis obliterans is the ultimate consequence of repeated injuries to lung allograft, related to immune and non-immune mechanisms. One hypothesis is that injury to the epithelium of small airways results in an abnormal repair characterised by recruitment of inflammatory cells and excessive fibro-proliferation. Acute cellular rejection is a risk factor for BOS and recent data also suggest that acute or chronic antibody-mediated rejection may play a role in the development of BOS [107]. Anti-HLA class I antibody binding to epithelial or endothelial cells induce cell proliferation and production of fibrogenic growth factors [108]. Graft damage related to rejection may expose cryptic antigens (e.g. k- $\alpha-1$ tubulin, collagen I and V) and induce autoimmunity, which is associated with increased risk of BOS [107]. It is possible that such autoimmune reaction may also be triggered by primary graft dysfunction related to ischaemia-reperfusion mechanisms [109], bacterial, viral or fungal infections [110], or GORD [111]. Epithelial damage may result in an excessive T-helper (Th)17 response, inducing neutrophil recruitment. Imbalance between Th17 lymphocytes and regulatory T-cells may determine the outcome: restitutio ad integrum or bronchiolitis obliterans [112]. Under some circumstances, epithelial damage may induce epithelial-to-mesenchymal transition in the airways, as observed in idiopathic pulmonary fibrosis [113].

Potential treatments of BOS may be more effective at an early (inflammatory) than at a later (fibrous) stage. Thus, early detection of BOS has been a major research interest for many groups. Assessment of ventilation heterogeneity using singlebreath nitrogen washout (SBNW) revealed that ventilation abnormalities 6-12 months before airflow abnormalities could be detected by spirometry in subjects with bilateral lung transplantation [114]. It has a good sensitivity and a very good negative predictive value for BOS [114]. Nitric oxide and carbon monoxide concentrations in exhaled breath have been correlated with airway neutrophilia in subjects with BOS, but their sensitivity is lower than SBNW [115]. Neutrophilia $(>20 \%)$ in bronchoalveolar lavage is predictive for future BOS in stable lung transplant recipients [116]. Exhaled breath condensates, induced sputum, bronchoalveolar lavage, and CT scans have all been evaluated for early detection of BOS. However, these tools cannot be recommended at present since they have not been validated in large multicenter studies.

Prevention of BOS is a major objective after lung transplantation. Pharmacokinetic optimisation of immunosuppressive therapy via therapeutic drug monitoring of immunosuppressive agents is important for prevention of acute rejection [117119]. Prevention of CMV pneumonia and community-acquired viral infection (e.g. via influenza vaccination) is of utmost importance. GORD must be detected and aggressively treated. Bronchoalveolar neutrophilia should be assessed, and azithromycin may be initiated in patients with increased neutrophilia [120]. A recent pilot study evaluating azithromycin- versus placebo-initiated therapy immediately after transplantation in 80 lung transplant recipients showed that incidence of bronchoalveolar neutrophilia and BOS were significantly reduced by azithromycin at 2 years post-transplantation [121]. Large multicenter studies are required to confirm these promising findings. Two retrospective studies have shown that treatments with statins inhibited class II HLA expression, diminished response to alloantigens and cytotoxic T-lymphocytes, reduced growth factor synthesis, and were associated with a reduction in BOS incidence and improved survival $[122,123]$. However, these data will require confirmation in randomised prospective studies.

When BOS is established, pharmacokinetic optimisation of immunosuppression may result in BOS stabilisation [124-126], but increasing the level of immunosuppression is generally unsuccessful and may be associated with increased risk of infections. Azithromycin may improve BOS in $\sim 50 \%$ of patients, especially in those with increased airway neutrophilia [127]. Total lymphoid irradiation may reduce FEV1 decline [128]. Lung retransplantation may be considered in some patients, although survival is lower than after the first transplantation [129].

\section{Bronchiolitis obliterans after allogeneic HSCT}

Bronchiolitis obliterans after allogeneic HSCT is usually considered as a chronic graft-versus-host (GVH) pulmonary manifestation [130]. As for bronchiolitis obliterans after lung transplantation, histopathological confirmation of diagnosis (which requires surgical biopsy) is rarely obtained, and BOS is suspected in patients with airflow obstruction and air trapping on CT scans, usually in the presence of extrapulmonary chronic GVH disease [130, 131]. In a recent large cohort study, the overall prevalence of BOS was $5.5 \%$ and increased to $14 \%$ in patients with chronic extrapulmonary GVH disease [132]. BOS onset occurred at a median time of 15-18 months after transplantation.

Histopathological studies show heterogeneous lesions in different patients, but also within the same patient, suggesting that lesions of different ages co-exist. Studies have found obliterative bronchiolitis or lymphocytic (cellular) bronchiolitis with abnormalities in bronchiolar epithelium [133, 134]. A recent study has suggested that lymphocytic bronchiolitis has better prognosis [134].

Several risk factors for BOS after allogeneic HSCT have been proposed in retrospective studies [132, 135-141]. The only risk factor that was consistently observed in these studies is chronic extrapulmonary GVH disease. A recent study has suggested the role of community-acquired respiratory viruses in triggering BOS [142].

Limited data exist on the pathogenesis of bronchiolitis obliterans after allogeneic HSCT. Most data come from studies performed on bronchiolitis obliterans after lung transplantation (see above) or on GVH disease. GVH disease is related to alloimmune reactions that occur in the presence of donor $\mathrm{T}$ lymphocytes [143]. Results obtained in humans and in animal models of GVH disease are somewhat controversial, but T- and B-cell abnormalities occur [143, 144]. In humans with bronchiolitis obliterans after allogeneic HSCT, peribronchiolar infiltrate was composed of CD8+T-lymphocytes in one patient [145] and of B-lymphocytes in another patient [146]. Genetic variations in bactericidal/permeability-increasing protein influence the risk of BOS after allogeneic HSCT [147]. Recently, a new 
murine model for bronchiolitis obliterans after allogeneic HSCT has reproduced bronchiolar abnormalities mimicking human disease [148], and may provide insights into the pathogenesis of bronchiolitis obliterans in humans.

BOS after HSCT is associated with reduced survival [132], which is poorer when BOS occurs soon after transplantation [149]. Bronchoalveolar lavage shows either lymphocytic alveolitis or neutrophilia, and is not required for diagnosis [150]. Atypical cells in bronchoalveolar lavage have been associated with chronic pulmonary GVH [151], but may only reflect epithelial injury by drugs utilised for pre-transplantation conditioning [152]. Air trapping on expiratory CT scans has been suggested as diagnostic criteria by the National Institutes of Health (NIH) consensus [130], although little data exist on its specificity in patients who have previously received many drugs with potential pulmonary toxicity.

The therapeutic approach of BOS after allogeneic HSCT is not well established. An increase in systemic immunosuppression (including oral steroids) may increase rates of severe, potentially lethal, infections and should not be advised [149]. Inhaled steroids and long-acting bronchodilators may improve lung function and pulmonary symptoms, and have very limited side-effects [153-155]. Lung transplantation may be proposed in selected patients without active chronic extrapulmonary GVH disease [156].

\section{Common variable immunodeficiency disorders}

CVID represent a heterogeneous group of conditions characterised by a low level of circulating IgG, IgA and/or IgM, and leading to increased susceptibility to infections [157]. Although the pathophysiology of CVID is not fully understood, it seems that B-lymphocytes fail to undergo normal maturation into plasma cells (which produce the antibodies). Abnormalities in T-lymphocytes are also frequently observed in patients with CVID [157]. The prevalence of CVID is estimated as approximately one in 30000 individuals. Clinical manifestations in patients with CVID are related to three mechanisms: 1) recurring infections related to the failure to produce sufficient antibody levels; 2) autoimmune diseases that are observed in up to $20 \%$ of patients and are probably related to immune dysregulation or to a defect in antigen clearance [94]; and 3) lymphoid hyperplasia with increased incidence of B-cell lymphoma, thymoma and solid cancer (especially stomach cancer) [158].

At the pulmonary level, recurring infections may be responsible for bronchiectasis (which is found in $4-52 \%$ of patients). Lymphoid hyperplasia and granulomatous lesions may infiltrate alveoli and bronchioles; this non-infectious complication of CVID is being called granulomatous-lymphocytic interstitial lung disease (GLILD) [14].

Follicular bronchiolitis is characteristic of small airways involvement in CVID: lymphoid follicles, containing a germinal centre with proliferating CD20+ B-lymphocytes, are found around the bronchioles and are associated with neutrophil recruitment and mucous obstruction [13, 14, 159]. Follicular bronchiolitis may be associated with other manifestations of GLILD, including LIP and granulomatous disease. LIP, which mostly contains CD3+ T-lymphocytes, has been found with a frequency of 3\% in patients with CVID [160]. Granulomatous disease is observed in $8-23 \%$ of patients with CVID, and largely mimics sarcoidosis with non-necrotising granuloma infiltrating both alveoli and airways [14, 157, 158, 161]. A recent case-control study has found that granulomatosis-associated CVID disorders have a specific clinical presentation, often characterised by crackles at auscultation, air bronchograms, halo signs and bronchiectasis on CT scans, and have worse prognosis compared to sarcoidosis [161]. Organising pneumonia has also been described in patients with CVID/GLILD [162, 163], and GLILD is often associated with autoimmune manifestations [94, 160, 164, 165].

Clinical manifestations of follicular bronchiolitis and GLILD in patients with CVIDs have been described in a cohort of 69 patients who were classified into three groups: Group 1 was composed of patients without respiratory symptoms or abnormalities on chest radiographs; Group 2 was composed of patients with respiratory symptoms but without diffuse radiographic abnormalities; and Group 3 was composed of patients with chronic respiratory symptoms and diffuse radiographic abnormalities [166]. Patients in Group 3 were divided into two subgroups on the basis of the histopathological pattern seen on lung biopsy: a subgroup that met GLILD criteria and a subgroup with all other types of ILD. The authors found that in patients with GLILD, follicular bronchiolitis, LIP and granulomatous disease often coexist and are associated with respiratory symptoms (dyspnoea, cough and, chest pain) and CT scan abnormalities (reticulo-nodular infiltrates, alveolar consolidation, ground-glass opacities and centrilobular micronodules) [166]. In some Group 2 patients, CT scan abnormalities (centrilobular nodules, tree-in-bud pattern and mosaic lung attenuation) often found in bronchiolitis were observed, suggesting that follicular bronchiolitis may exist in the absence of infiltrative lung disease [166].

Few studies have evaluated the associations between CT scan abnormalities and pulmonary function tests in patients with CVID. In a cohort of 65 patients, correlation was found between bronchial wall thickening, mucoid impaction and mosaic lung attenuation on the one hand and airway obstruction (FEV1 and FEV1/FVC) on the other [167]. Low diffusing capacity of the lung for carbon monoxide (DLCO) was associated with bronchial wall thickening and linear opacities. In another study of a cohort of 51 children with CVID, the authors reported correlations between air trapping on CT scans and distal airway obstruction, as measured by FEF25-75\% [168].

Among CVID patients, those with GLILD have worst survival. Death is often related to extrapulmonary localisations of granulomatous disease (e.g. liver cirrhosis) and to autoimmune manifestations [166]. Treatments of follicular bronchiolitis or GLILD are not well established. Although systemic steroids are often prescribed, their efficacy is inconstant. Individual case reports have suggested possible efficacy of other immunosuppressive drugs (ciclosporin A, anti-tumour necrosis factor- $\alpha$ ) in patients with GLILD [169, 170].

\section{Diffuse panbronchiolitis}

Diffuse panbronchiolitis is a rare disorder, which has been initially described in Japan and mostly affects east Asian people, although a few cases have been described in Caucasians. Diffuse 
panbronchiolitis has been the topic of recent reviews [171, 172], and will not be extensively discussed here.

Diffuse panbronchiolitis occurs in the fourth to sixth decade of life and is clinically characterised by recurrent sinus and airway infection, associated with the rapid development of bronchiolitis and bronchiectasis. CT scan abnormalities include centrilobular nodules that may be connected to distal branching bronchovascular structures (tree-in-bud pattern) and may be associated with cyst and bronchiectasis [173]. The disease is usually diffuse, affecting both upper and lower lobes. Airflow limitation and hyperinflation may worsen rapidly, leading to respiratory failure and death.

Histopathological examination indicates that the disease is focused on respiratory bronchioles, where it affects all layers of the bronchial wall. The inflammatory infiltrate is composed of neutrophils, CD8 T-lymphocytes and foamy macrophages. The airway epithelium may be damaged and shows extensive goblet cell hyperplasia with secretion of MUC5AC and MUC5B mucins [174, 175]. Genetic predisposition related to specific HLA genotypes or polymorphisms in MUC5B mucin have been suggested [176].

Prolonged treatment with low-dose macrolides has been shown to often result in dramatic improvement in some patients and sometimes in complete recovery [177]. In a recent study of 24 patients with diffuse panbronchiolitis treated for 3 months with erythromycin, decreased air trapping on CT scan correlated with an improvement of centrilobular nodules, suggesting an effect of therapy on obstructive lesions in small airways [178]. In a recent study, the authors performed repeated multiple nitrogen washout tests to evaluate acinar (Sacin) and conductive (Scond) ventilation heterogeneity in a single patient with diffuse panbronchiolitis treated with azithromycin [179]. The authors found that after 5 months of azithromycin treatment Scond fell within the normal limit, whereas Sacin was still abnormal after 16 months of treatment, suggesting that macrolides cannot reverse the acinar component of ventilation heterogeneity in diffuse panbronchiolitis [179].

\section{Drug-induced small airways disease}

Lung or airway abnormalities may occur during treatments with many different drugs (www.pneumotox.com) and lead to multiple patterns. Here, we will limit the discussion to the very limited number of drugs that have been associated with bronchiolitis, excluding organising pneumonia (sometimes called BOOP) [180, 181] and drug-induced bronchospasm [182]. Drugs associated with bronchiolitis include some treatments of rheumatoid arthritis ( $D$-penicillamine, chrysotherapy and tiopronin) and busulfan-based conditioning for allogeneic haematopoietic cell transplantation. These medications were, or are still, prescribed for conditions already responsible for bronchiolitis (see above), which leads to difficulties in establishing a firm causal relationship.

The role of $D$-penicillamine in the induction of bronchiolitis has been suspected since 1976 [183]. Most of the descriptions of $D$-penicillamine-associated bronchiolitis were reported in the 1980s [184] but not since, which probably reflects the currently limited use of the drug. Devouassoux et al. [55] reported 25 cases of severe obliterative bronchiolitis in rheumatoid arthritis and found that 12 patients had previously received
$D$-penicillamine, one patient had received tiopronin and 10 patients had received chrysotherapy. Patients who had received $D$-penicillamine had significantly lower FEV1 than those who did not $(800 \pm 320 \mathrm{~mL}$ versus $1240 \pm 320 \mathrm{~mL}$, respectively, $\mathrm{p}<0.01)$. Histopathological examination in patients who had received $D$-penicillamine found follicular or constrictive bronchiolitis, sometimes co-existing in the same patient [55]. Onset of symptoms occurred at a mean 6-7 months after starting $D$-penicillamine, which may be faster than in patients with rheumatoid arthritis who did not receive $D$ penicillamine [185]. A case of obliterative bronchiolitis was also reported in a patient with localised scleroderma treated with D-penicillamine [186].

Chrysotherapy has also been suspected to induce bronchiolitis. TOMIOKA and KING [81] have analysed 140 published cases of gold-induced pulmonary disease; gold was prescribed in $80 \%$ of cases for rheumatoid arthritis. The authors found four cases of bronchiolitis. A case of constrictive bronchiolitis obliterans was reported 4 months after initiating intra-muscular chrysotherapy for psoriatic arthritis [187]. Fatal bronchiolitis was also reported 6 months after initiating chrysotherapy in a patient with juvenile rheumatoid arthritis [188]. Tiopronin, another drug sometimes utilised in the treatment of rheumatoid arthritis, has been associated with bronchiolitis in a very limited number of cases [55, 189].

Busulfan is an alkylating antineoplastic agent, which has long been associated with drug-induced interstitial pneumonia [190]. Busulfan, together with cyclophosphamide and/or total body irradiation, has been utilised for destroying the recipient's immune system before allogeneic bone marrow transplantation. In a prospective study, RINGDEN et al. [191] found that bronchiolitis with airflow limitation occurred in $26 \%$ of patients who received a busulfan-based regimen versus $5 \%$ of patients who received cyclophosphamide-total body irradiation. In a retrospective analysis of a registry of patients receiving allogeneic HSCT for leukaemia, the authors found that previous treatment with busulfan was associated with an increased risk for bronchiolitis obliterans (HR 2.24, 95\% CI 1.39-3.60, p $<0.009$ [192]). A recent retrospective study of 1145 patients with allogeneic haematopoietic cell transplantation found bronchiolitis obliterans in $5.5 \%$ of patients and reported no association with busulfan [132].

Sauropus androgynus is a shrub grown in some tropical regions and is used as a leaf vegetable in various countries (e.g. southeast China, Indonesia, Malaysia and Vietnam). In 1996, an outbreak of bronchiolitis obliterans associated with the consumption of Sauropus androgynus was reported in 278 patients in Taiwan [193]. The clinical presentation associated progressive dyspnoea and persistent cough with ground-glass opacities and bronchiectasis on CT scan examination and irreversible airflow limitation. Patients had absorbed uncooked Sauropus androgynus juice or dry powder (usually used for alleged anorexigen properties) for a mean period of 6 months. Response to prednisolone was very limited; nine patients died and eight patients underwent lung transplantation. A dose-response relationship was established between the consumption of Sauropus androgynus and irreversible obstructive ventilatory defect, further reinforcing causality [194]. Five additional cases have been subsequently reported in Japan 
[195]. Because papaverine is a major component of Sauropus androgynus, it has been suspected to play a role in the development of bronchiolitis obliterans under these circumstances and repeated intratracheal instillation of papaverine indeed mimicked human bronchiolitis obliterans in rats [196]. However, papaverine is widely used for its antispasmodic properties and no case of papaverine-associated bronchiolitis has been reported, making the relevance of these animal findings questionable.

A single report suggests an association of topotecan, a topoisomerase I inhibitor used in the treatment of ovarian carcinoma and nonsmall cell lung cancer, with bronchiolitis obliterans [197]. In a series of nine cases describing respiratory complications associated with dasatinib, one patient had received dasatinib therapy after occurrence of bronchiolitis obliterans ascribed to imatinib [198]. Repeated aspiration of particulate matter (e.g. talc, cellulose, crospovidone and sodium polystyrene sulfonate), for medical purposes [199], or psyllium (a laxative compound) [200] may also cause bronchiolitis.

\section{Environmental or occupational exposure}

\section{Hypersensitivity pneumonitis}

Hypersensitivity pneumonitis is one of the most frequent causes of small airways diseases. It is usually due to the inhalation of organic dust (e.g. mouldy hay or straw) but can also occur with the inhalation of chemical compounds (e.g. isocyanates) [201, 202]. Pathologically, hypersensitivity pneumonitis is characterised by an inflammatory process with granulomatous infiltration of the lung interstitium and small airways. Although hypersensitivity pneumonitis is often considered an interstitial lung disease, small airways disease is constant and sometimes predominates [203, 204].

Farmer's lung (related to exposure to hay or straw) and pigeon breeder's disease (related to exposure to bird dejections) are among the most frequent forms of hypersensitivity pneumonitis, but novel environmental exposures can also be involved. For example, exposure to household moulds (related to increasing use of air conditioning and humidifiers) has been associated with hypersensitivity pneumonitis [205]. Exposure to Mycobacterium avium intracellulare in hot tubs (hot tub lung) [206-209] or to Mycobacterium immunogenum in metalworking fluids used in the industrial sector (machine operator's lung) [210] have also been associated with hypersensitivity pneumonitis.

A number of diagnostic criteria for hypersensitivity pneumonitis have been described. Six criteria may be used to suspect hypersensitivity pneumonitis and avoid lung biopsy: 1) evidence of exposure to appropriate antigen; 2) detection of serum antibody to this antigen; 3) recurrence of symptoms (fever, chills, cough, dyspnoea, etc.); 4) often occurring within 4-8 h after antigen exposure; 5) presence of inspiratory crackles; and 6) weight loss [211]. In Type 1 (acute) hypersensitivity pneumonitis, the onset of symptoms (fever and chills) occurs a few hours after antigen exposure, whereas Type 2 hypersensitivity pneumonitis is usually related to chronic antigen exposure and characterised by digital clubbing and pulmonary function test abnormalities (with restrictive and/or obstructive pattern, hypoxaemia and low DLCO), and may evolve into pulmonary fibrosis and/or emphysema despite antigen avoidance [212].
Structural abnormalities in hypersensitivity pneumonitis have been described in subjects with farmer's lung or pigeon breeder's disease [213-216]. In acute or subacute disease lung inflammation is characterised by cellular infiltrates containing CD8+T-lymphocytes, neutrophils, macrophages, plasmocytes and mast cells. This cellular infiltrate may form granulomas surrounding and/or compressing bronchioles, eventually leading to bronchial obstruction. Giant cells are often present, even in the absence of granuloma. Bronchiolitis obliterans with endobronchial proliferation may be found in $10-50 \%$ of cases [217]. In chronic disease, peribronchiolar fibrosis leading to obliterative bronchiolitis may occur, and is generally associated with pulmonary fibrosis.

Chest radiographs may be normal in $20 \%$ of cases of hypersensitivity pneumonitis, underlining the importance of CT scans [218]. CT scan abnormalities may reflect cellular infiltration with ground-glass opacities and ill-defined centrilobular nodules corresponding to granulomatous lesions [204, 219]. They may also reflect ventilation abnormalities related to bronchiolitis with mosaic attenuation on inspiration and air trapping on expiration. Emphysema and fibrosis mimicking usual interstitial pneumonia may be found in chronic disease [220, 221].

Clinical manifestations of hypersensitivity pneumonitis include chronic cough and sputum production in up to $50 \%$ of patients [222-225]. Nonspecific bronchial hyperresponsiveness [226, 227] and wheezing may also be prevalent in subjects with recent hypersensitivity pneumonitis, especially in dairy farmers [228, 229].

Pulmonary function tests in acute hypersensitivity pneumonitis usually show a restrictive pattern with low DLCO [201]. In subacute hypersensitivity pneumonitis, RV may be normal or even increased and correlated with air trapping on CT scans [219]. Airflow limitation (defined by an FEV1/FVC ratio $<70 \%$ ) occurred in $10-17 \%$ of patients with farmer's lung or pigeon breeder's disease at diagnosis [223, 225, 228]. Following acute or subacute hypersensitivity pneumonitis, 30-65\% of patients remain symptomatic and $\sim 30 \%$ develop chronic respiratory failure. Long-term longitudinal cohorts indicate that emphysema with airflow limitation often occurs during follow-up [221, 230, 231], especially in farmer's lung and in hypersensitivity pneumonitis related to intermittent allergen exposure. Chronic exposure to low concentrations of antigen (e.g. pigeon's breeder lung) usually leads to pulmonary fibrosis.

\section{Bronchiolitis related to other environmental exposures}

Smoking exposure may cause histopathological lesions in large airways and alveoli, but also in small airways. Bronchiolitis induced by tobacco-smoke exposure, also called respiratory bronchiolitis, may be isolated or associated with ILD and is usually classified among interstitial pneumonitis. Respiratory bronchiolitis is usually asymptomatic, but CT scans may show ill-defined centrilobular nodules. When respiratory bronchiolitis is associated with interstitial pneumonia, CT scans usually show ground-glass opacities and centrilobular lobules with upper lobe predominance. Diagnosis is easily obtained in a smoking patient due to bronchoalveolar lavage, which shows very high cellularity $\left(>10^{6}\right.$ cells $\left.\cdot \mathrm{mL}^{-1}\right)$ comprised of macrophages. The prognosis is usually related to other consequences of tobacco-smoke exposure including respiratory insufficiency. 
Although asbestos has been suspected to induce bronchiolitis, a recent study did not confirm this hypothesis [232]. Bronchiolitis induced by chronic inhalation of mineral particles or acute inhalation of toxic gas (such as $\mathrm{NO}_{2}$ ) are other examples of damage to small airways due to environmental exposures. Pathophysiological mechanisms are probably different from hypersensitivity pneumonitis and damage to bronchioles is exclusive or predominant. Finally, complex lung exposure observed in some rare cases (such as in the World Trade Center disaster [233] or during war [234]) may lead to less wellcharacterised patterns of small airway diseases.

\section{CONCLUSION}

Located at a transitional zone between larger airways and lung interstitium, small airways may be affected in a wide variety of pathophysiological conditions. Although major progress has been achieved in the recognition of small airways disease, diagnosis still remains difficult in 2013. Noninvasive methods for the diagnosis have been greatly improved by progress in CT scan imaging, and novel image analysis software may even increase our ability to monitor small airways disease without the requirement of lung biopsy [19]. Environmental and drug exposures are changing rapidly and these changes may lead to the occurrence of new conditions associated with novel drugs or environmental exposures or to improvement of existing disease. Treatment of small airways diseases is not well established due to the wide variety of causal factors and their often late diagnosis. Better and earlier identification of small airways diseases should improve the possibilities to propose earlier treatment intervention. For example, very little information is currently available on potential effects on small airways disease of targeted therapies used in connective tissue diseases. Collaborative research will be required to improve knowledge in these relatively rare diseases.

\section{STATEMENT OF INTEREST}

Conflict of interest information can be found alongside the online version of this article at err.ersjournals.com

\section{ACKNOWLEDGEMENTS}

The author's affiliations are as follows: P-R. Burgel: Service de Pneumologie, Hôpital Cochin, AP-HP, Université Paris Descartes, Paris, France; A. Bergeron: Service de Pneumologie, Hôpital Saint Louis, AP-HP, Université Paris Diderot, UMR-S717 INSERM, Paris, France; J. de Blic: Service de Pneumologie Pediatrique, Hôpital NeckerEnfants Malades, AP-HP, Université Paris Descartes, Paris, France; P. Bonniaud: Service de Pneumologie, CHU du Bocage, Université de Bourgogne, Dijon, France; A. Bourdin: Service de Pneumologie, Hôpital Arnaud de Villeneuve, CHU Montpellier, Montpellier, France; P. Chanez: Service de Pneumologie, Hôpital Ste-Marguerite, AP-HM, INSERM UMR 6020, Université de la Méditerranée, Marseille, France; T. Chinet: Service de Pneumologie, Hôpital Ambroise Paré, AP-HP, Boulogne, France; J-C. Dalphin: Service de Pneumologie, Hôpital Jean Minjoz, Besançon, France; P. Devillier: Service de Pneumologie, Hôpital Foch, UPRES EA 220, Université Versailles Saint-Quentin, Suresnes, France; A. Deschildre: Service de Pneumologie Pediatrique, Hôpital Jeanne de Flandres, CHRU de Lille, Lille, France; A. Didier: Service de Pneumologie, Hôpital Larrey, Université de Toulouse, Toulouse, France; M. Kambouchner: Service de Pneumologie, Hôpital Avicenne, AP-HP, Université Paris 13, Bobigny, France; C. Knoop; Dept of Chest Medicine, Erasme University Hospital, Université Libre de Bruxelles, Brussels, Belgium; F. Laurent: Service de Radiologie, CHU de Bordeaux, Université Victor Segalen Bordeaux 2, INSERM U
1045 Bordeaux, France; H. Nunes: Service de Pneumologie, Hôpital Avicenne, AP-HP, Université Paris 13, Bobigny, France; T. Perez: Service de Pneumologie, CHRU de Lille, Hôpital Albert Calmette, Lille, France; N. Roche: Service de Pneumologie, Hôpitaux Universitaires Paris Centre, AP-HP, Université Paris Descartes, Paris, France; I. TillieLeblond ${ }^{\dagger}$ : Service de Pneumologie, CHRU de Lille, Hôpital Albert Calmette, Lille, France; D. Dusser: Service de Pneumologie, Hôpital Cochin, AP-HP, Université Paris Descartes, Paris, France.

We dedicate this manuscript to honour the legacy of our dear coauthor and friend Isabelle Tillie-Leblond (1965-2013), for her outstanding contribution to respiratory disease care and research, and her unconditional friendship.

\section{REFERENCES}

1 Burgel PR. The role of small airways in obstructive airway diseases. Eur Respir Rev 2011; 20: 23-33.

2 Burgel PR, Bourdin A, Chanez P, et al. Update on the role of distal airways in COPD. Eur Respir Rev 2011; 20: 7-22.

3 Burgel PR, de Blic J, Chanez P, et al. Update on the roles of distal airways in asthma. Eur Respir Rev 2009; 18: 80-95.

4 Burgel PR, Montani D, Danel C, et al. A morphometric study of mucins and small airway plugging in cystic fibrosis. Thorax 2007; 62: 153-161.

5 Tiddens H, Donaldson SH, Rosenfeld M, et al. Cystic fibrosis lung disease starts in the small airways: can we treat it more effectively? Pediatric Pulmonology 2010; 45: 107-117.

6 Hogg JC. Pathophysiology of airflow limitation in chronic obstructive pulmonary disease. Lancet 2004; 364: 709-721.

7 Cosio M, Ghezzo H, Hogg JC, et al. The relations between structural changes in small airways and pulmonary-function tests. N Engl J Med 1978; 298: 1277-1281.

8 Ryu JH, Myers JL, Swensen SJ. Bronchiolar disorders. Am J Respir Crit Care Med 2003; 168: 1277-1292.

9 Devakonda A, Raoof S, Sung A, et al. Bronchiolar disorders: a clinico-radiological diagnostic algorithm. Chest 2010; 137: 938-951.

10 Rice A, Nicholson AG. The pathologist's approach to small airways disease. Histopathol 2009; 54: 117-133.

11 Visscher DW, Myers JL. Bronchiolitis. The pathologist's perspective. Proc Am Thor Soc 2006; 3: 41-47.

12 Yousem SA. Small airways disease. Pathol Annu 1991; 26: 109-143.

13 Yousem SA, Colby TV, Carrington CB. Follicular bronchitis/ bronchiolitis. Hum Pathol 1985; 16: 700-706.

14 Park JH, Levinson AI. Granulomatous-lymphocytic interstitial lung disease (GLILD) in common variable immunodeficiency (CVID). Clin Immunol 2010; 134: 97-103.

15 Masuda T, Ishikawa Y, Akasaka Y, et al. Follicular bronchiolitis associated with Legionella pneumophilia infection. Pediatr Pathol Mol Med 2002; 21: 517-524.

16 Burgel PR, Nadel JA. Epidermal growth factor receptormediated innate immune responses and their roles in airway diseases. Eur Respir J 2008; 32: 1068-1081.

17 Fukuoka J, Franks TJ, Colby TV, et al. Peribronchiolar metaplasia: a common histologic lesion in diffuse lung disease and a rare cause of interstitial lung disease: clinicopathologic features of 15 cases. Am J Surg Pathol 2005; 29: 948-954.

18 Rowan C, Hansell DM, Renzoni E, et al. Diffuse cystic lung disease of unexplained cause with coexistent small airway disease: a possible cause relationship? Am J Surg Pathol 2012; 36: 228-234.

19 Galbán CJ, Han MK, Boes JL, et al. Computed tomography-based biomarker provides unique signature for diagnosis of COPD phenotypes and disease progression. Nat Med 2012; 18: 1711-1715.

20 Hansell DM, Rubens MB, Padley SP, et al. Obliterative bronchiolitis: individual CT signs of small airways disease and functional correlation. Radiology 1997; 203: 721-726. 
21 Tillie-Leblond, Crestani B, Perez T, et al. Voies aériennes distales et maladies de système [The distal airways is systemic disease.] Rev Mal Resp 2012; 29: 1254-1263.

22 Martin C, Frija J, Burgel PR. Dysfunctional lung anatomy and small airways degeneration in COPD. Int J COPD 2013; 8: 7-13.

23 Larranaga C, Kajon A, Villagra E, et al. Adenovirus surveillance on children hospitalized for acute lower respiratory infections in Chile (1988-1996). J Med Virol 2000; 60: 342-346.

24 Videla C, Carballal G, Kajon A. Genomic analysis of adenovirus isolated from Argentinian children with acute lower respiratory infections. J Clin Virol 1999; 14: 67-71.

25 Castro-Rodriguez JA, Daszenies C, Garcia M, et al. Adenovirus pneumonia in infants and factors for developing bronchiolitis obliterans: a 5-year follow-up. Pediatr Pulmonol 2006; 41: 947-953.

26 Lang WR, Howden CW, Laws J, et al. Bronchopneumonia with serious sequelae in children with evidence of adenovirus type 21 infection. Br Med J 1969; 1: 73-79.

27 Daxbock F, Brunner G, Popper H, et al. A case of lung transplantation following Mycoplasma pneumoniae infection. Eur J Clin Microbiol Infect Dis 2002; 21: 318-322.

28 Kim CK, Kim SW, Kim JS, et al. Bronchiolitis obliterans in the 1990s in Korea and the United States. Chest 2001; 120: 1101-1106.

29 Villarreal Garcia-Lomas M, Vargas Nunez JA, Romero Pizarro Y, et al. Bronquiolitos obliterante con neumonía organizativa asociada a infección por Mycoplasma pneumoniae [Bronchiolitis obliterans with organizing pneumonia associated with $\mathrm{Myco-}$ plasma pneumoniae infection.]. Rev Clin Esp 2002; 202: 519-520.

30 Colom AJ, Teper AM, Vollmer WM, et al. Risk factors for the development of bronchiolitis obliterans in children with bronchiolitis. Thorax 2006; 61: 503-506.

31 Fischer GB, Sarria EE, Mattiello R, et al. Post infectious bronchiolitis obliterans in children. Paediatr Respir Rev 2010; 11 233-239.

32 Cazzato S, Poletti V, Bernardi F, et al. Airway inflammation and lung function decline in childhood post-infectious bronchiolitis obliterans. Pediatr Pulmonol 2008; 43: 381-390.

33 Teper AM, Kofman CD, Maffey AF, et al. Lung function in infants with chronic pulmonary disease after severe adenoviral illness. J Pediatr 1999; 134: 730-733.

34 Cordier JF. Organising pneumonia. Thorax 2000; 55: 318-328.

35 Hall WJ, Hall CB, Speers DM. Respiratory syncytial virus infection in adults: clinical, virologic, and serial pulmonary function studies. Ann Intern Med 1978; 88: 203-205.

36 Rollins S, Colby T, Clayton F. Open lung biopsy in Mycoplasma pneumoniae pneumonia. Arch Pathol Lab Med 1986; 110: 34-41.

37 Sato P, Madtes DK, Thorning D, et al. Bronchiolitis obliterans caused by Legionella pneumophila. Chest 1985; 87: 840-842.

38 Kuru T, Lynch JP 3rd. Nonresolving or slowly resolving pneumonia. Clin Chest Med 1999; 20: 623-651.

39 White ES, Tazelaar HD, Lynch JP 3rd. Bronchiolar complications of connective tissue diseases. Semin Respir Crit Care Med 2003; 24: 543-566.

40 Hatron PY, Tillie-Leblond I, Launay D, et al. Pulmonary manifestations of Sjögren's syndrome. Presse Med 2011; 40: e49-e64.

41 Hayakawa H, Sato A, Imokawa S, et al. Bronchiolar disease in rheumatoid arthritis. Am J Respir Crit Care Med 1996; 154: 1531-1536.

42 Vandenplas O, Casel S, Delos $\mathrm{M}$, et al. Granulomatous bronchiolitis associated with Crohn's disease. Am J Respir Crit Care Med 1998; 158: 1676-1679.

43 Nunes H, Brillet PY, Valeyre D, et al. Imaging in sarcoidosis. Semin Respir Crit Care Med 2007; 28: 102-120.

44 Tanaka N, Kim JS, Newell JD, et al. Rheumatoid arthritis-related lung diseases: CT findings. Radiology 2004; 232: 81-91.

45 Cortet B, Perez T, Roux N, et al. Pulmonary function tests and high resolution computed tomography of the lungs in patients with rheumatoid arthritis. Ann Rheum Dis 1997; 56: 596-600.
46 Devaraj A, Wells AU, Hansell DM. Computed tomographic imaging in connective tissue diseases. Semin Respir Crit Care Med 2007; 28: 389-397.

47 Franquet T, Diaz C, Domingo P, et al. Air trapping in primary Sjogren syndrome: correlation of expiratory CT with pulmonary function tests. J Comput Assist Tomogr 1999; 23: 169-173.

48 Franquet T, Gimenez A, Monill JM, et al. Primary Sjogren's syndrome and associated lung disease: CT findings in 50 patients. AJR Am J Roentgenol 1997; 169: 655-658.

49 Franquet T, Muller NL. Disorders of the small airways: highresolution computed tomographic features. Semin Respir Crit Care Med 2003; 24: 437-444

50 Hassan WU, Keaney NP, Holland CD, et al. High resolution computed tomography of the lung in lifelong non-smoking patients with rheumatoid arthritis. Ann Rheum Dis 1995; 54: 308-310.

51 Ito I, Nagai S, Kitaichi M, et al. Pulmonary manifestations of primary Gougerot-Sjögren's Syndrome. A clinical, radiologic, and pathologic study. Am J Respir Crit Care Med 2005; 171 632-638.

52 Perez T, Remy-Jardin M, Cortet B. Airways involvement in rheumatoid arthritis: clinical, functional, and HRCT findings. Am J Respir Crit Care Med 1998; 157: 1658-1665.

53 Taouli B, Brauner MW, Mourey I, et al. Thin-section chest CT findings of primary Sjogren's syndrome: correlation with pulmonary function. Eur Radiol 2002; 12: 1504-1511.

54 Watanabe M, Naniwa T, Hara M, et al. Pulmonary manifestations in Sjogren's syndrome: correlation analysis between chest computed tomographic findings and clinical subsets with poor prognosis in 80 patients. J Rheumatol 2010; 373: 65-73.

55 Devouassoux $\mathrm{G}$, Cottin V, Liote $\mathrm{H}$, et al. Characterisation of severe obliterative bronchiolitis in rheumatoid arthritis. Eur Respir J 2009; 33: 1053-1061.

56 Papiris SA, Saetta M, Turato G, et al. CD4-positive T-lymphocytes infiltrate the bronchial mucosa of patients with GougerotSjögren's syndrome. Am J Respir Crit Care Med 1997; 156: 637-641.

57 Amin K, Lúdvíksdóttir D, Janson C, et al. Bronchial hyperresponsiveness. Inflammation and structural changes in the airways of patients with primary Sjögren's syndrome. Respir Med 2001; 95: 904-910.

58 Nakanishi M, Fukuoka J, Tanaka T, et al. Small airway disease associated with Sjögren's syndrome: clinico-pathological correlations. Respir Med 2011; 105: 1931-1938.

59 Fortoul TI, Cano-Valle F, Oliva E, et al. Follicular bronchiolitis in association with connective tissue diseases. Lung 1985; 163: 305-314

60 Newball HH, Brahim SA. Chronic obstructive airway disease in patients with Sjögren's syndrome. Am Rev Respir Dis 1977; 115: 295-304.

61 Mialon $\mathrm{P}$, Barthélémy L, Sébert $\mathrm{P}$, et al. A longitudinal study of lung impairment in patients with primary Sjögren's syndrome. Clin Exp Rheumatol 1997; 15: 349-354.

62 Gudbjornsson B, Hedenstrom H, Stalenheim G, et al. Bronchial hyperresponsiveness to methacholine in patients with primary Sjogren's syndrome. Ann Rheum Dis 1991; 50: 36-40.

63 La Corte R, Potena A, Bajocchi G, et al. Increased bronchial responsiveness in primary Sjogren's syndrome. A sign of tracheobronchial involvement. Clin Exp Rheumatol 1991; 9: 125-130.

64 Potena A, La Corte R, Fabbri LM, et al. Increased bronchial responsiveness in primary and secondary Sjogren's syndrome. Eur Respir J 1990; 3: 548-553.

65 Ludviksdottir D, Janson C, Bjornsson E, et al. Different airway responsiveness profiles in atopic asthma, nonatopic asthma, and Sjogren's syndrome. BHR Study Group. Bronchial hyperresponsiveness. Allergy 2000; 55: 259-265.

66 Borie R, Schneider S, Debray MP, et al. Severe chronic bronchiolitis as the presenting feature of primary Sjögren's syndrome. Respir Med 2011; 105: 130-136. 
67 Koyama M, Johkoh T, Honda O, et al. Pulmonary involvement in primary Sjogren's syndrome: spectrum of pulmonary abnormalities and computed tomography findings in 60 patients. J Thorac Imaging 2001; 16: 290-296.

68 Lohrmann C, Uhl M, Warnatz K, et al. High-resolution CT imaging of the lung for patients with primary Sjogren's syndrome. Eur Radiol 2004; 52: 137-143.

69 Papiris SA, Maniati M, Constantopoulos SH, et al. Lung involvement in primary Sjogren's syndrome is mainly related to the small airway disease. Ann Rheum Dis 1999; 58: 61-64.

70 Uffmann M, Kiener HP, Bankier AA, et al. Lung manifestation in asymptomatic patients with primary Sjogren syndrome: assessment with high resolution $\mathrm{CT}$ and pulmonary function tests. J Thorac Imaging 2001; 16: 282-289.

71 Stalenheim G, Gudbjornsson B. Anti-inflammatory drugs do not alleviate bronchial hyperreactivity in Sjogren's syndrome. Allergy 1997; 52: 423-427.

72 Meijer JM, Pijpe J, Vissink A, et al. Treatment of primary Sjogren syndrome with rituximab: extended follow-up, safety and efficacy of retreatment. Ann Rheum Dis 2009; 68: 284-285.

73 Puechal X, Bienvenu T, Genin E, et al. Mutations of the cystic fibrosis gene in patients with bronchiectasis associated with rheumatoid arthritis. Ann Rheum Dis 2011; 70: 653-659.

74 Puechal X, Fajac I, Bienvenu T, et al. Increased frequency of cystic fibrosis deltaF508 mutation in bronchiectasis associated with rheumatoid arthritis. Eur Respir J 1999; 13: 1281-1287.

75 Bienvenu T, Sermet-Gaudelus I, Burgel PR, et al. CFTR channel dysfunction in non-cystic fibrosis bronchiectasis. Am J Respir Crit Care Med 2010; 181: 1078-1084.

76 Geddes DM, Webley M, Emerson PA. Airways obstruction in rheumatoid arthritis. Ann Rheum Dis 1979; 38: 222-225.

77 Howling SJ, Hansell DM, Wells AU, et al. Follicular bronchiolitis: thin-section CT and histologic findings. Radiology 1999; 212: 637-642.

78 Leslie KO, Trahan S, Gruden J. Pulmonary pathology of the rheumatic diseases. Semin Respir Crit Care Med 2007; 28: 369-378.

79 Mori S, Koga Y, Sugimoto M. Small airway obstruction inpatients with rheumatoid arthritis. Mod Rheumatol 2011; 21: 164-173.

80 Stein HB, Patterson AC, Offer RC, et al. Adverse effects of Dpenicillamine in rheumatoid arthritis. Ann Intern Med 1980; 92: 24-29.

81 Tomioka R, King TE Jr. Gold-induced pulmonary disease: clinical features, outcome, and differentiation from rheumatoid lung disease. Am J Respir Crit Care Med 1997; 155: 1011-1020.

82 Homma S, Kawabata M, Kishi K, et al. Diffuse panbronchiolitis in rheumatoid arthritis. Eur Respir J 1998; 12: 444-452.

83 Tsuchiya $\mathrm{Y}$, Takayanagi $\mathrm{N}$, Sugiura $\mathrm{H}$, et al. Lung diseases directly associated with rheumatoid arthritis and their relationship to outcome. Eur Respir J 2011; 37: 1411-1417.

84 Cortot $A B$, Cottin V, Miossec $\mathrm{P}$, et al. Improvement of refractory rheumatoid arthritis-associated constrictive bronchiolitis with etanercept. Respir Med 2005; 99: 511-514.

85 Hoffmann RM, Kruis W. Rare extraintestinal manifestations of inflammatory bowel disease. Inflamm Bowel Dis 2004; 10: 140-147.

86 Mahadeva R, Walsh G, Flower CD, et al. Clinical and radiological characteristics of lung disease in inflammatory bowel disease. Eur Respir J 2000; 15: 41-48.

87 Eaton TE, Lambie N, Wells AU. Bronchiectasis following colectomy for Crohn's disease. Thorax 1998; 53: 529-531.

88 Tzanakis N, Samiou M, Bouros D, et al. Small airways function in patients with inflammatory bowel disease. Am J Respir Crit Care Med 1998; 157: 382-386.

89 Camus P, Piard F, Ashcroft T, et al. The lung in inflammatory bowel disease. Medicine (Baltimore) 1993; 72: 151-183.

90 Estenne M, Maurer JR, Boehler A, et al. Bronchiolitis obliterans syndrome 2001: an update of the diagnostic criteria. J Heart Lung Transplant 2002; 21: 297-310.
91 Christie JD, Edwards LB, Kucheryavaya AY, et al. The Registry of the International Society for Heart and Lung Transplantation: twenty-seventh official adult lung and heart-lung transplant report-2010. J Heart Lung Transplant 2010; 29: 1104-1118.

92 Copeland CAF, Snyder LD, Zaas DW, et al. Survival after bronchiolitis obliterans syndrome among bilateral lung transplant recipients. Am J Respir Crit Care Med 2010; 182: 784-789.

93 Vanaudenaerde BM, Meyts I, Vos R, et al. A dichotomy in bronchiolitis obliterans syndrome after lung transplantation revealed by azithromycin therapy. Eur Resp J 2008; 32: 832-843.

94 Agarwal S, Cunningham-Rundles C. Autoimmunity in common variable immunodeficiency. Curr Allergy Asthma Rep 2009; 9: 347-352.

95 Hachem RR, Khalifah AP, Chakinala MM, et al. The significance of a single episode of minimal acute rejection after lung transplantation. Transplantation 2005; 80: 1406-1413.

96 Hopkins PM, Aboyoun CL, Chhajed PN, et al. Association of minimal rejection in lung transplant recipients with obliterative bronchiolitis. Am J Respir Crit Care Med 2004; 170: 1022-1026.

97 Khalifah AP, Hachem RR, Chakinala MM, et al. Minimal acute rejection after lung transplantation: a risk for bronchiolitis obliterans syndrome. Am J Transplant 2005; 5: 2022-2030.

98 Knoop C, Estenne M. Chronic allograft dysfunction. Clin Chest Med 2011; 32: 311-326.

99 Girnita AL, Duquesnoy R, Yousem SA, et al. HLA-specific antibodies are risk factors for lymphocytic bronchiolitis and chronic lung allograft dysfunction. Am J Transplant 2005; 5: 131-138.

100 Snyder LD, Finlen-Copeland CA, Turbyfill WJ, et al. Cytomegalovirus pneumonitis is a risk for bronchiolitis obliterans syndrome in lung transplantation. Am J Respir Crit Care Med 2010; 181: 1391-1396.

101 Tamm M, Aboyoun CL, Chhajed PN, et al. Treated cytomegalovirus pneumonia is not associated with bronchiolitis obliterans syndrome. Am J Respir Crit Care Med 2004; 170: 1120-1123.

102 Kumar D, Erdman D, Keshavjee S, et al. Clinical impact of community-acquired respiratory viruses on bronchiolitis obliterans after lung transplant. Am J Transplant 2005; 5: 2031-2036.

$103 \mathrm{Vu}$ DL, Bridevaux PO, Aubert JD, et al. Respiratory viruses in lung transplant recipients: a critical review and pooled analysis of clinical studies. Am J Transplant 2011; 11: 1071-1078.

104 Cantu E, Appel JZ, Hartwig MG, et al. Early fundoplication prevents chronic allograft dysfunction in patients with gastroesophageal reflux disease. Ann Thorac Surg 2004; 78: 1142-1151.

105 Davis RD, Lau CL, Eubanks S, et al. Improved lung allograft function after fundoplication in patients with gastroesophageal reflux disease undergoing lung transplantation. I Thorac Cardiovasc Surg 2003; 125: 533-542.

106 Hartwig MG, Anderson DJ, Onaitis MW, et al. Fundoplication after lung transplantation prevents the allograft dysfunction associated with reflux. Ann Thorac Surg 2011; 92: 462-469.

107 Saini D, Weber J, Ramachandran S, et al. Alloimmunity-induced autoimmunity as a potential mechanism in the pathogenesis of chronic rejection of human lung allografts. J Heart Lung Transplant 2011; 30: 624-631.

108 Jaramillo A, Smith CR, Maruyama T, et al. Anti-HLA class I antibody binding to airway epithelial cells induces production of fibrogenic growth factors and apoptotic cell death: a possible mechanism for bronchiolitis obliterans syndrome. Hum Immunol 2003; 64: 521-529.

109 Bharat A, Saini D, Steward N, et al. Antibodies to self-antigens predispose to primary lung allograft dysfunction and chronic rejection. Ann Thorac Surg 2010; 90: 1094-1100.

110 Nakajima T, Palchevsky V, Perkins DL, et al. Lung transplantation: infection, inflammation, and the microbiome. Semin Immunopathol 2011; 33: 135-156. 
111 Bobadilla JL, Jankowska-Gan E, Xu Q, et al. Reflux-induced collagen type $\mathrm{v}$ sensitization potential mediator of bronchiolitis obliterans syndrome. Chest 2010; 138: 363-370.

112 Neujahr DC, Larsen CP. Regulatory $\mathrm{T}$ cells in lung transplantation-an emerging concept. Semin Immunopathol 2011; 33: 117-127.

113 Borthwick LA, Sunny SS, Oliphant V, et al. Pseudomonas aeruginosa accentuates epithelial-to-mesenchymal transition in the airway. Eur Respir J 2011; 37: 1237-1247.

114 Estenne M, Van Muylem A, Knoop C, et al. Detection of obliterative bronchiolitis after lung transplantation by indexes of ventilation distribution. Am J Respir Crit Care Med 2000; 162: 1047-1051.

115 Van Muylem A, Knoop C, Estenne M. Early detection of chronic pulmonary allograft dysfunction by exhaled biomarkers. Am J Respir Crit Care Med 2007; 175: 731-736.

116 Neurohr C, Huppmann P, Samweber B, et al. Prognostic value of bronchoalveolar lavage neutrophilia in stable lung transplant recipients. J Heart Lung Transplant 2009; 28: 468-474.

117 Macpherson RI, Cumming GR, Chernick V. Unilateral hyperlucent lung: a complication of viral pneumonia. J Can Assoc Radiol 1969; 20: 225-231.

118 Monchaud C, Marquet P. Pharmacokinetic optimization of immunosuppressive therapy in thoracic transplantation: Part I. Clin Pharmacokinet 2009; 48: 419-462.

119 Monchaud C, Marquet P. Pharmacokinetic optimization of immunosuppressive therapy in thoracic transplantation: Part II. Clin Pharmacokinet 2009; 48: 489-516.

120 Verleden GM, Vanaudenaerde BM, Dupont LJ, et al. Azithromycin reduces airway neutrophilia and interleukin-8 in patients with bronchiolitis obliterans syndrome. Am J Respir Crit Care Med 2006; 174: 566-570.

121 Vos R, Vanaudenaerde BM, Verleden SE, et al. A randomised controlled trial of azithromycin to prevent chronic rejection after lung transplantation. Eur Respir J 2011; 37: 164-172.

122 Johnson BA, Iacono AT, Zeevi A, et al. Statin use is associated with improved function and survival of lung allografts. Am J Respir Crit Care Med 2003; 167: 1271-1278.

$123 \mathrm{Li} \mathrm{YJ}$, Gottlieb J, Ma DH, et al. Graft-protective effects of the HMG-CoA reductase inhibitor pravastatin after lung transplantation - a propensity score analysis with 23 years of follow-up. Transplantation 2011; 92: 486-492.

124 Groetzner J, Wittwer T, Kaczmarek I, et al. Conversion to sirolimus and mycophenolate can attenuate the progression bronchiolitis obliterans syndrome and improves renal lung transplantation function after lung transplantation. Transplantation 2006; 81: 355-360.

125 Robertson AGN, Griffin SM, Murphy DM, et al. Targeting allograft injury and inflammation in the management of postlung transplant bronchiolitis obliterans syndrome. Am J Transplant 2009; 9: 1272-1278.

126 Sarahrudi $\mathrm{K}$, Estenne $\mathrm{M}$, Corris $\mathrm{P}$, et al. International experience with conversion from cyclosporine to tacrolimus for acute and chronic lung allograft rejection. J Thorac Cardiovasc Surg 2004; 127: 1126-1132.

127 Yates B, Murphy DM, Forrest IA, et al. Azithromycin reverses airflow obstruction in established bronchiolitis obliterans syndrome. Am J Respir Crit Care Med 2005; 172: 772-775.

128 Fisher AJ, Rutherford RM, Bozzino J, et al. The safety and efficacy of total lymphoid irradiation in progressive bronchiolitis obliterans syndrome after lung transplantation. Am J Transplant 2005; 5: 537-543.

129 Kawut SM, Lederer DJ, Keshavjee S, et al. Outcomes after lung retransplantation in the modern era. Am J Respir Crit Care Med 2008; 177: 114-120.

130 Filipovich AH, Weisdorf D, Pavletic S, et al. National Institutes of Health consensus development project on criteria for clinical trials in chronic graft-versus-host disease: I. Diagnosis and staging working group report. Biol Blood Marrow Transplant 2005; 11: 945-956.

131 Chien JW, Duncan S, Williams KM, et al. Bronchiolitis obliterans syndrome after allogeneic hematopoietic stem cell transplantation-an increasingly recognized manifestation of chronic graftversus-host disease. Biol Blood Marrow Transplant 2010; 16: Suppl. 1, S106-S114.

$132 \mathrm{Au} \mathrm{BK}, \mathrm{Au}$ MA, Chien JW. Bronchiolitis obliterans syndrome epidemiology after allogeneic hematopoietic cell transplantation. Biol Blood Marrow Transplant 2011; 17: 1072-1078.

133 Yousem SA. The histological spectrum of pulmonary graftversus-host disease in bone marrow transplant recipients. Hum Pathol 1995; 26: 668-675.

134 Holbro A, Lehmann T, Girsberger S, et al. Lung histology predicts outcome of bronchiolitis obliterans syndrome after hematopoietic stem cell transplantation. Biol Blood Marrow Transplant 2013 [In press DOI 10.1016/J.BBMT.2013.03.017].

135 Chan CK, Hyland RH, Hutcheon MA, et al. Small-airways disease in recipients of allogeneic bone marrow transplants. An analysis of 11 cases and a review of the literature. Medicine (Baltimore) 1987; 66: 327-340.

136 Clark JG, Crawford SW, Madtes DK, et al. Obstructive lung disease after allogeneic marrow transplantation. Clinical presentation and course. Ann Intern Med 1989; 111: 368-376.

137 Dudek AZ, Mahaseth H, DeFor TE, et al. Bronchiolitis obliterans in chronic graft-versus-host disease: analysis of risk factors and treatment outcomes. Biol Blood Marrow Transplant 2003; 9: 657-666.

138 Marras TK, Chan CK, Lipton JH, et al. Long-term pulmonary function abnormalities and survival after allogeneic marrow transplantation. Bone Marrow Transplant 2004; 33: 509-517.

139 Marras TK, Szalai JP, Chan CK, et al. Pulmonary function abnormalities after allogeneic marrow transplantation: a systematic review and assessment of an existing predictive instrument. Bone Marrow Transplant 2002; 30: 599-607.

140 Palmas A, Tefferi A, Myers JL, et al. Late-onset noninfectious pulmonary complications after allogeneic bone marrow transplantation. Br J Haematol 1998; 100: 680-687.

141 Philit F, Wiesendanger T, Archimbaud E, et al. Post-transplant obstructive lung disease ("bronchiolitis obliterans"): a clinical comparative study of bone marrow and lung transplant patients. Eur Respir J 1995; 8: 551-558.

142 Erard V, Chien JW, Kim HW, et al. Airflow decline after myeloablative allogeneic hematopoietic cell transplantation: the role of community respiratory viruses. J Infect Dis 2006; 193: 1619-1625.

143 Coghill JM, Sarantopoulos S, Moran TP, et al. Effector CD4 ${ }^{+} \mathrm{T}$ cells, the cytokines they generate, and GVHD: something old and something new. Blood 2011; 117: 3268-3276.

144 Schroeder MA, DiPersio JF. Mouse models of graft-versus-host disease: advances and limitations. Dis Model Mech 2011; 4: 318-333.

145 Streichenberger N, Peyrol S, Philit F, et al. Constrictive bronchiolitis obliterans. Characterisation of fibrogenesis and lysyl oxidase expression patterns. Virchows Arch 2001; 439: 78-84.

146 Lorillon G, Robin M, Meignin V, et al. Rituximab in bronchiolitis obliterans after haematopoietic stem cell transplantation. Eur Respir J 2011; 38: 470-472.

147 Chien JW, Zhao LP, Hansen JA, et al. Genetic variation in bactericidal/permeability-increasing protein influences the risk of developing rapid airflow decline after hematopoietic cell transplantation. Blood 2006; 107: 2200-2207.

148 Panoskaltsis-Mortari A, Tram KV, Price AP, et al. A new murine model for bronchiolitis obliterans post-bone marrow transplant. Am J Respir Crit Care Med 2007; 176: 713-723. 
149 Bergeron A, Godet C, Chevret S, et al. Bronchiolitis obliterans syndrome after allogeneic hematopoietic SCT: phenotypes and prognosis. Bone Marrow Transplant 2012 [In press DOI: 10.1038/ bmt.2012.241].

150 St John RC, Gadek JE, Tutschka PJ, et al. Analysis of airflow obstruction by bronchoalveolar lavage following bone marrow transplantation. Implications for pathogenesis and treatment. Chest 1990; 98: 600-607.

151 Rochat I, Posfay-Barbe KM, Kumar N, et al. Bronchoalveolar cytology for diagnosing pulmonary GVHD after bone marrow transplant in children. Pediatr Pulmonol 2008; 43: 697-702.

152 Gulbahce HE, Baker KS, Kumar P, et al. Atypical cells in bronchoalveolar lavage specimens from bone marrow transplant recipients. A potential pitfall. Am J Clin Pathol 2003; 120: 101-106.

153 Bashoura L, Gupta S, Jain A, et al. Inhaled corticosteroids stabilize constrictive bronchiolitis after hematopoietic stem cell transplantation. Bone Marrow Transplant 2008; 41: 63-67.

154 Bergeron A, Belle A, Chevret S, et al. Combined inhaled steroids and bronchodilatators in obstructive airway disease after allogeneic stem cell transplantation. Bone Marrow Transplant 2007; 39: 547-553.

155 Wolff D, Gerbitz A, Ayuk F, et al. Consensus conference on clinical practice in chronic graft-versus-host disease (GVHD): first-line and topical treatment of chronic GVHD. Biol Blood Marrow Transplant 2010; 16: 1611-1628.

156 Koenecke C, Hertenstein B, Schetelig J, et al. Solid organ transplantation after allogeneic hematopoietic stem cell transplantation: a retrospective, multicenter study of the EBMT. Am J Transplant 2010; 10: 1897-1906.

157 Chapel H, Cunningham-Rundles C. Update in understanding common variable immunodeficiency disorders (CVIDs) and the management of patients with these conditions. $\mathrm{Br} J$ Haematol 2009; 145: 709-727.

158 Cunningham-Rundles $C$. How I treat common variable immune deficiency. Blood 2010; 116: 7-15.

159 Nicholson AG, Wotherspoon AC, Diss TC, et al. Reactive pulmonary lymphoid disorders. Histopathology 1995; 26: 405-412.

160 Chapel H, Lucas M, Lee M, et al. Common variable immunodeficiency disorders: division into distinct clinical phenotypes. Blood 2008; 112: 277-286.

161 Bouvry D, Mouthon L, Brillet PY, et al. Granulomatosisassociated common variable immunodeficiency disorder: a case control study versus sarcoidosis. Eur Resp J 2013; 41: 115-122.

162 Kaufman J, Komorowski R. Bronchiolitis obliterans organizing pneumonia in common variable immunodeficiency syndrome. Chest 1991; 100: 552-553.

163 Wislez M, Sibony M, Naccache JM, et al. Organizing pneumonia related to common variable immunodeficiency. Case report and literature review. Respiration 2000; 67: 467-470.

164 Cunningham-Rundles C. Autoimmune manifestations in common variable immunodeficiency. J Clin Immunol 2008; 28: Suppl. $1, \mathrm{~S} 42-\mathrm{S} 45$.

165 Cunningham-Rundles C. Autoimmunity in primary immune deficiency: taking lessons from our patients. Clin Exp Immunol 2011; 164: Suppl. 2, S6-S11.

166 Bates CA, Ellison MC, Lynch DA, et al. Granulomatouslymphocytic lung disease shortens survival in common variable immunodeficiency. J Allergy Clin Immunol 2004; 114: 415-421.

167 Gregersen S, Aalokken TM, Mynarek G, et al. High resolution computed tomography and pulmonary function in common variable immunodeficiency. Respir Med 2009; 103: 873-880.

168 van Zeggeren L, van de Ven AA, Terheggen-Lagro SW, et al. High-resolution computed tomography and pulmonary function in children with common variable immunodeficiency. Eur Respir J 2011; 38: 1437-1443.
169 Davies CW, Juniper MC, Gray W, et al. Lymphoid interstitial pneumonitis associated with common variable hypogammaglobulinaemia treated with cyclosporin A. Thorax 2000; 55: 88-90.

170 Hatab AZ, Ballas ZK. Caseating granulomatous disease in common variable immunodeficiency treated with infliximab. J Allergy Clin Immunol 2005; 116: 1161-1162.

171 Kudoh S, Keicho N. Diffuse panbronchiolitis. Clin Chest Med 2012; 33: 297-305.

172 Poletti V, Casoni G, Chilosi M, et al. Diffuse panbronchiolitis. Eur Resp J 2006; 28: 862-871.

173 Akira M, Kitatani F, Lee YS, et al. Diffuse panbronchiolitis: evaluation with high-resolution CT. Radiology 1988; 168: 433-438.

$174 \mathrm{Kim} \mathrm{JH}$, Juang $\mathrm{KH}$, Han JH, et al. Relation of epidermal growth factor receptor expression to mucus hypersecretion in diffuse panbronchiolitis. Chest 2004; 126: 888-895.

175 Kamio K, Matsushita I, Hijikata M, et al. Promoter analysis and aberrant expression of the MUC5B gene in diffuse panbronchiolitis. Am J Respir Crit Care Med 2005; 171: 949-957.

176 Keicho N, Hijikata M. Genetic predisposition to diffuse panbronchiolitis. Respirology 2011; 16: 581-588.

177 Friedlander AL, Albert RK. Chronic macrolide therapy in inflammatory airways diseases. Chest 2010; 138: 1202-1212.

178 Yamada G, Igarashi T, Itoh E, et al. Centrilobular nodules correlate with air trapping in diffuse panbronchiolitis during erythromycin therapy. Chest 2001; 120: 198-202.

179 Hanon S, Verbanck S, Schuermans D, et al. Evidence of improved small airways function after azithromycin treatment in diffuse panbronchiolitis. Respiration 2012; 84: 75-79.

180 Camus P, Bonniaud P, Fanton A, et al. Drug-induced and iatrogenic infiltrative lung disease. Clin Chest Med 2004; 25 479-519.

181 Epler GR. Drug-induced bronchiolitis obliterans organizing pneumonia. Clin Chest Med 2004; 25: 89-94.

182 Babu KS, Marshall BG. Drug-induced airway diseases. Clin Chest Med 2004; 25: 113-122.

183 Brewerton D. D-Penicillamine. Br Med J 1976; 2: 1507

184 Epler GR, Snider GL, Gaensler EA, et al. Bronchiolitis and bronchitis in connective tissue disease. A possible relationship to the use of penicillamine. JAMA 1979; 242: 528-532.

185 Wolfe F, Schurle DR, Lin JJ, et al. Upper and lower airway disease in penicillamine treated patients with rheumatoid arthritis. I Rheumatol 1983; 10: 406-410.

186 Boehler A, Vogt P, Speich R, et al. Bronchiolitis obliterans in a patient with localized scleroderma treated with $D$-penicillamine. Eur Respir J 1996; 9: 1317-1319.

187 Schwartzman KJ, Bowie DM, Yeadon C, et al. Constrictive bronchiolitis obliterans following gold therapy for psoriatic arthritis. Eur Respir J 1995; 8: 2191-2193.

188 Pegg SJ, Lang BA, Mikhail EL, et al. Fatal bronchiolitis obliterans in a patient with juvenile rheumatoid arthritis receiving chrysotherapy. J Rheumatol 1994; 21: 549-551.

189 Demaziere A, Maugars Y, Chollet S, et al. Non-fatal bronchiolitis obliterans possibly associated with tiopronin. A case report with long-term follow-up. Br J Rheumatol 1993; 32: 172-174.

190 Massin F, Fur A, Reybet-Degat O, et al. La pneumopathie du busulfan [Busulfan-induced pneumopathy]. Rev Mal Respir 1987; 4: 3-10.

191 Ringden $\mathrm{O}$, Remberger $\mathrm{M}$, Ruutu $\mathrm{T}$, et al. Increased risk of chronic graft-versus-host disease, obstructive bronchiolitis, and alopecia with busulfan versus total body irradiation: long-term results of a randomized trial in allogeneic marrow recipients with leukemia. Nordic Bone Marrow Transplantation Group. Blood 1999; 93: 2196-2201.

192 Santo Tomas LH, Loberiza FR Jr, Klein JP, et al. Risk factors for bronchiolitis obliterans in allogeneic hematopoietic stem-cell transplantation for leukemia. Chest 2005; 128: 153-161. 
193 Lai RS, Chiang AA, Wu MT, et al. Outbreak of bronchiolitis obliterans associated with consumption of Sauropus androgynus in Taiwan. Lancet 1996; 348: 83-85.

194 Hsiue TR, Guo YL, Chen KW, et al. Dose-response relationship and irreversible obstructive ventilatory defect in patients with consumption of Sauropus androgynus. Chest 1998; 113: 71-76.

195 Oonakahara K, Matsuyama W, Higashimoto I, et al. Outbreak of bronchiolitis obliterans associated with consumption of Sauropus androgynus in Japan - alert of food-associated pulmonary disorders from Japan. Respiration 2005; 72: 221.

196 Svetlecic J, Molteni A, Herndon B. Bronchiolitis obliterans induced by intratracheal papaverine: a novel animal model. Lung 2004; 182: 119-134.

197 Edgerton CC, Gilman M, Roth BJ. Topotecan-induced bronchiolitis. South Med J 2004; 97: 699-701.

198 Bergeron A, Rea D, Levy V, et al. Lung abnormalities after dasatinib treatment for chronic myeloid leukemia: a case series. Am I Respir Crit Care Med 2007; 176: 814-818.

199 Mukhopadhyay S, Katzenstein AL. Pulmonary disease due to aspiration of food and other particulate matter: a clinicopathologic study of 59 cases diagnosed on biopsy or resection specimens. Am J Surg Pathol 2007; 31: 752-759.

200 Janoski MM, Raymond GS, Puttagunta L, et al. Psyllium aspiration causing bronchiolitis: radiographic, high-resolution $\mathrm{CT}$, and pathologic findings. AJR Am J Roentgenol 2000; 174: 799-801.

201 Girard M, Lacasse Y, Cormier Y. Hypersensitivity pneumonitis. Allergy 2009; 64: 322-334.

202 Bourke SJ, Dalphin JC, McSharry CP, et al. Hypersensitivity pneumonitis: current concepts. Eur Respir J 2001; 18: 81s-92s.

203 Selman M, Perez-Padilla R. Airflow obstruction and airway lesions in hypersensitivity pneumonitis. Clin Chest Med 1993; 14: 699-714.

204 Selman M, Vargas MH. Airway involvement in hypersensitivity pneumonitis. Curr Opin Pulm Med 1998; 4: 9-15.

205 Hanak V, Golbin JM, Ryu JH. Causes and presenting features in 85 consecutive patients with hypersensitivity pneumonitis. Mayo Clin Proc 2007; 82: 812-816.

206 Glazer CS, Martyny JW, Lee B, et al. Nontuberculous mycobacteria in aerosol droplets and bulk water samples from therapy pools and hot tubs. J Occup Environ Hyg 2007; 4: 831-840.

207 Hanak V, Kalra S, Aksamit TR, et al. Hot tub lung: presenting features and clinical course of 21 patients. Respir Med 2006; 100: 610-615.

208 Hartman TE, Jensen E, Tazelaar HD, et al. CT findings of granulomatous pneumonitis secondary to Mycobacterium avium intracellulare inhalation: "hot tub lung". Am J Roentgenol 2007; 188: 1050-1053.

209 Sood A, Sreedhar R, Kulkarni P, et al. Hypersensitivity pneumonitis-like granulomatous lung disease with nontuberculous mycobacteria from exposure to hot water aerosols. Environ Health Perspect 2007; 115: 262-266.

210 Tillie-Leblond I, Grenouillet F, Reboux G, et al. Hypersensitivity pneumonitis associated to metalworking fluids contaminated by mycobacteria. Eur Respir J 2011; 37: 640-647.

211 Lacasse Y, Selman M, Costabel U, et al. Clinical diagnosis of hypersensitivity pneumonitis. Am J Respir Crit Care Med 2003; 168: 952-958.

212 Lacasse Y, Selman M, Costabel U, et al. Classification of hypersensitivity pneumonitis: a hypothesis. Int Arch Allergy Immunol 2009; 149: 161-166.

213 Coleman A, Colby TV. Histologic diagnosis of extrinsic allergic alveolitis. Am J Surg Pathol 1988; 12: 514-518.

214 Iwata M, Colby TV, Kitaichi M. Diffuse panbronchiolitis: diagnosis and distinction from various pulmonary diseases with centrilobular interstitial foam cell accumulations. Hum Pathol 1994; 25: 357-363.

215 Perez-Padilla R, Gaxiola M, Salas J, et al. Bronchiolitis in chronic pigeon breeder's disease: morphologic evidence of a spectrum of small airway lesions in hypersensitivity pneumonitis induced by avian antigens. Chest 1996; 110: 371-377.

216 Reyes CN, Wenzel FJ, Lawton BR, et al. The pulmonary pathology of farmer's lung disease. Chest 1982; 81: 142-146.

217 Kawanami O, Basset F, Barrios R, et al. Hypersensitivity pneumonitis in man: light- and electron-microscopic studies of 18 lung biopsies. Am J Pathol 1983; 110: 275-289.

218 Hodgson MJ, Parkinson DK, Harf M. Chest $X$ rays in hypersensitivity: a meta-analysis of secular trend. Am J Ind Med 1989; 16: 45-53.

219 Hansell DM, Wells AU, Padley SP, et al. Hypersensitivity pneumonitis: correlation of individual CT patterns with functional abnormalities. Radiology 1996; 199: 123-128.

220 Remy-Jardin M, Remy J, Wallaert B, et al. Subacute and chronic bird breeder hypersensitivity pneumonitis: sequential evaluation with CT and correlation with lung function tests and bronchoalveolar lavage. Radiology 1993; 189: 111-118.

221 Cormier $\mathrm{Y}$, Brown M, Worthy S, et al. High-resolution computed tomographic characteristics in acute farmers' lung and in its follow-up. Eur Respir J 2000; 16: 56-60.

222 Bourke SJ, Anderson K, Lynch PP, et al. Chronic simple bronchitis in pigeon fanciers: relationship of cough with expectoration to avian exposure and pigeon breeder's disease. Chest 1989; 95: 598-601.

223 Bourke SJ, Carter R, Anderson K, et al. Obstructive airway disease in non-smoking subjects with pigeon fanciers' lung. Clin Exp Allergy 1989; 19: 629-632.

224 Dalphin JC, Debieuvre D, Pernet D, et al. Prevalence and risk factors for chronic bronchitis and farmer's lung in French dairy farmers. Br J Ind Med 1993; 50: 941-944.

225 Depierre A, Dalphin JC, Pernet D, et al. Epidemiological study of farmer's lung in five districts of the French Doubs province. Thorax 1988; 43: 429-435.

226 Freedman PM, Ault B. Bronchial hyperreactivity to methacholine in farmers' lung disease. J Allergy Clin Immunol 1981; 67: 59-63.

227 Mönkäre S, Haahtela T, Ikonen M, et al. Bronchial hyperreactivity to inhaled histamine in patients with farmers' lung. Lung $1981 ; 145-151$.

228 Kokkarinen JI, Tukiainen HO, Terho EO. Recovery of pulmonary function in farmer's lung : a five-year follow-up study. Am Rev Respir Dis 1993; 147: 793-796.

229 Kokkarinen JI, Tukiainen HO, Terho EO. Asthma in patients with farmer's lung during a five-year follow-up. Scand J Work Environ Health 1997; 23: 149-151.

230 Braun SR, doPico GA, Tsiatis A, et al. Famer's lung disease: longterm clinical and physiologic outcome. Am Rev Respir Dis 1979; 119: 185-191.

231 Fink JN, Ortega HG, Reynolds HY, et al. Needs and opportunities for research in hypersensitivity pneumonitis. Am J Respir Crit Care Med 2005; 171: 792-798.

232 Ameille J, Letourneux M, Paris C, et al. Does asbestose exposure cause airway obstruction, in the absence of confirmed asbestosis? Am J Respir Crit Care Med 2010; 182: 526-530.

233 de la Hoz RE. Occupational lower airway disease in relation to World Trade Center inhalation exposure. Cur Opin Allergy Clin Immunol 2011; 11: 97-102.

234 King MS, Eisenberg R, Newman JH, et al. Constrictive bronchiolitis in soldiers returning from Iraq and Afghanistan. N Engl J Med 2011; 365: 222-230. 